Research Article

\title{
Design of a Personal Mobility Device for Elderly Users
}

\author{
Natthanon Phannil (iD) and Chaiyan Jettanasen (iD) \\ Faculty of Engineering, King Mongkut's Institute of Technology Ladkrabang, Bangkok 10520, Thailand \\ Correspondence should be addressed to Chaiyan Jettanasen; chaiyan.je@kmitl.ac.th
}

Received 28 September 2020; Revised 12 January 2021; Accepted 2 February 2021; Published 13 February 2021

Academic Editor: Ilias Maglogiannis

Copyright (C) 2021 Natthanon Phannil and Chaiyan Jettanasen. This is an open access article distributed under the Creative Commons Attribution License, which permits unrestricted use, distribution, and reproduction in any medium, provided the original work is properly cited.

\begin{abstract}
The ageing society has resulted in imbalances in the population age ratio. The ratio of working-age people was less than that of elderly people resulting in a shortage of elderly caregivers and increased healthcare costs. Although the lifestyle the elderly remains the same, their physical abilities are reduced, requiring them to rely on special equipment when traveling in order to gain more control and safety. Therefore, the Elderly Personal Mobility Device (EPMD) is developed using Internet of Things (IoT) technology to reduce the burden of caregivers, provide freedom and safety for elderly travelers, assess air pollution risks, and alert the occurrence of emergency events. The EPMD is designed in terms of structure, electrical equipment, and sensor systems. First, the shapes, sizes, and thicknesses of the carbon steel used for construction of the EPMD structure are calculated by using SolidWorks software. Next, the electric equipment is carefully selected to meet the requirements of actual use. Finally, the sensor system is designed to monitor the EPMD status and air quality using IoT devices to create a data interface and big data for elderly health service development, as well as an air quality map with distributed measuring stations and a charging station detection system for future use.
\end{abstract}

\section{Introduction}

Many countries around the world are currently facing rapid growth in the number of ageing citizens due to low birth rates, longer life expectancies, and ageing of the baby boomers, especially in developed countries. According to the World Health Organization [1], the segment of the population aged 60 years or older is expected to increase by at least $3 \%$ per year. In 2017, the $60+$ population around the world was 963 million, which was $13 \%$ of the overall population.

The proportion of people aged 60 and above in Asia is projected to increase dramatically and is expected to be the highest proportion of $60+$ people in the world. According to the Global AgeWatch Index [2,3], Japan has the largest senior population and will be the first country in the world to become a super-aged society, which means that more than $20 \%$ of their total population will be aged 65 years and older. South Korea is also facing a situation similar to that of Japan; the elderly population is expected to be $31.4 \%$ in 2030 , which will be the second largest senior population in Asia.
Moreover, China is facing the problem of a child policy that will result in a decline of the population, will create a huge ageing gap, and will shrink the labour force. The elderly population of China will increase from $15.2 \%$ in 2015 to $25.3 \%$ in 2030 .

The demographic situation around the world has moved into the era of smart city planning and implementation. One of the major challenges is to meet the needs of an increasingly ageing population. In areas such as mobility, healthcare, and community services, technological innovation will play a pivotal role in upgrading homes and the urban environments in which an increasing elderly population will live. The World Health Organization has created the Global Age-Friendly Cities guide [4, 5]; however, it is worth noting that many of the items on the wish list also improve urban life for the general population.

Solutions vary from high tech to simple and often an ingenious combination. Globally, governments around the world are beginning to adopt stricter planning regulations. Many cities are embracing the notion of the smart city, offering opportunities via subsidies, initiative schemes, and focus 
groups that can assist in planning, implementation, and trials of new ideas. Aside from physical measures, several cities, such as Taipei, Barcelona, Malmö, and Mexico City, have focussed on reducing the Information and Communication Technology (ICT) divide that can prevent senior citizens from accessing smart solutions by developing digital literacy plans aimed at the elderly. For mobility and accessibility, such plans can help senior citizens to master simple computer skills that increase their independence, opening up new lines of communication to people that may otherwise be isolated.

Another vital contribution to mental and physical health is the ability to navigate a city independently. No matter how well city planning has been carried out, this is a constant challenge for those with limited mobility. Localised air quality warnings from Internet of Things (IoT) systems, $[6,7]$ such as smart lampposts [6] or smart benches [7], could also be incorporated to help the elderly avoid venturing out on particularly smoggy days. Various applications developed for those with limited vision can also serve the elderly. For example, BlindSquare [8-10] is an app that is designed to help the visually impaired navigate cities by describing the environment, warning of intersections, providing directions, and recommending possible places of interest-services that prove useful for the elderly.

A mobility vehicle [11-14] is an essential option to facilitate an expanded travel range for elderly people and to increase safety. While the vehicle is aimed at providing seamless and rapid commuter travel, it may allow tasks such as grocery shopping to be completed without needing to consider the weight of groceries on the walk home or to provide the ability to manage a small case for a weekend away without having to resort to using a taxi for short trips. This can help to keep the elderly in the loop with upcoming community events and to increase their confidence in navigating new spaces and venues, knowing that their needs will be served. It is clear that, as the populations of many countries shift towards an ageing society, advances in AI, IoT, and other technologies will be integral for adapting urban life to the needs of the elderly.

In Thailand, the number of elderly people is steadily increasing, they are living longer, and there is a decline in the birth rate. As indicated in the report of the Department of Older Persons of The Ministry of Social Development and Human Security in 2019 [15], Thailand has a relatively high older population (aged 60 years and over), up to $19 \%$ of the country's population. The average age of this population was 61 years in 1972, but in 2019, the average age had increased to 76 years due to medical advancement. The proportion of the elderly population in Thailand will increase to $19.8 \%$ in 2022 . The Office of the Thai Health Promotion Foundation has estimated the elderly population (aged 60 years and over), and it was found that by 2036, the elderly population of Thailand will consist of $33 \%$ of the total population. Many elderly people have physical disabilities, so that the problems of the ageing society are relevant and require serious solutions.

Although the society of Thailand is ageing, there are few studies on ageing society support, especially in the field of elderly travel. Most elderly people cannot use a commercial vehicle for daily travel because of their reduced ability to control the vehicle. Commercial vehicles move at high speeds, are large, and are difficult to control and move, while elderly people often travel short distances within residential areas. Therefore, the use of special vehicles operating at low speeds, that are small, and that are designed of use by the elderly represent a viable solution. One of the interesting classes of special vehicles is micromobility, which consists of small, lightweight vehicles operating at speeds typically below $25 \mathrm{~km} / \mathrm{h}$ that are driven by users personally. Micromobility devices include bicycles, e-bikes, electric scooters, electric skateboards, shared bicycles, and electric pedalassisted (pedelec) bicycles. A micromobility device should have a gross vehicle weight of less than $500 \mathrm{~kg}(1,100 \mathrm{lb})$.

Generally, most micromobility is used in the form of a small scooter, which is lightweight and portable, and has a speed of $5-10 \mathrm{~km} / \mathrm{h}$ with a distance of $10-15 \mathrm{~km} /$ charge. These micromobility devices are suitable for short trips where the user must have great physical ability and mobility; thus, they are not suitable for the elderly. More recently, larger micromobility vehicles, that can travel longer distances, with more carrier weight, have been developed, which are more responsive to the needs of the elderly.

The speed of these vehicles does not exceed $25 \mathrm{~km} / \mathrm{h}$ with a distance of $20-30 \mathrm{~km} /$ charge, which supports the lifestyle of the elderly, such as residential area travel and shopping. Micromobility is mainly designed for transporting people, so there has been little development in communication or data transfer. Recently, the applications of IoT technology and information systems have had a great effect on the user's choice of micromobility. In addition, autonomous vehicles $[16,17]$ have been developed that require sensors, processing, and communication systems. This has resulted in the concept of using IoT technology and information systems in conjunction with micromobility for use in Thailand. Micromobility for the elderly should be designed according to the elderly lifestyle.

Most of the developed IoT systems focus on healthcare for the elderly, reducing the burden of caregivers, and preventing accidents. Many researchers have developed monitoring systems [18-23] to meet these needs, which consist of health data measurement systems [18-20] and mobile assistive devices [21-23]. Bongisizwe et al. [19] designed Healthcare Monitoring Systems (HMSs) using Zigbee to detect heart disease, high blood pressure, and other cardiovascular diseases. Wang et al. [20] designed a human health monitoring system using Narrowband IoT (NB-IoT) to send data of heartbeats, body temperature, and location to caregivers and family in emergencies. Yang et al. [21] designed a smart crutch for elderly people for real-time monitoring of falling, heart rate, and location.

Not only is IoT technology used for measuring health data, it is also useful for monitoring harmful pollution in the surrounding environment. Many researchers have developed air pollution detection systems [24-32] that directly affect the elderly because they are more adversely affected by pollution. Therefore, the development of air pollution detection systems not only helps the elderly to assess their own risk but also creates an air pollution map for each area, leading to future solutions. An IoT crowd sensing platform [24] offers a set of 
services to citizens by exploiting a network of bicycles as IoT probes based on a survey conducted to identify the most interesting bike-enabled services. The Smart Bike platform provides real-time remote geolocation of users' bikes, antitheft services, information about travel routes, and air pollution monitoring. In [25-28], a cost effective, stand-alone, multiparameter, the urban climate monitoring system is developed for analysis of major air pollutants in the atmosphere based on IoT and cloud computing using the Arduino Uno board. Mahammad [29] designed an air monitoring system using a node MCU module, an optical dust sensor, and a Blink application as a cloud platform.

Micromobility development has focused on the design of the structure, the control system, the charging system, and the motor, but there have not been significant improvements in micromobility for the elderly. Micromobility for the elderly requires functional development to meet their needs and to reduce the burden of caregivers, resulting in greater stability and safety. Although the development of devices to monitor elderly health [18-23] and to assess air quality [24-32] will be developed using IoT technology, in which these devices are often permanently installed and unable to track the outdoor activities of the elderly. Therefore, the development of micromobility with sensor systems and IoT technology that can transmit data, ambient air quality assessment, and emergency alerts is an interesting idea for building age-friendly cities in the future.

This study describes the development of an Elderly Personal Mobility Device (EPMD) with a sensor system to display and notify the EPMD status and air quality detection via IoT technology. The EPMD design includes the structure, electrical equipment, and sensor system to ensure the safety of the elderly and reduce the burden of caregivers. The EPMD structure is considered in terms of the shape, size, and thickness of carbon steel and is analysed using the SolidWorks program to consider the values of weight, strain, stress, displacement, and cost. Next, the propulsion power is calculated by the dynamic equation and used to select the electric equipment. Finally, the sensor system is designed to monitor the EPMD status and air quality detection for elderly care efficiency. The sensor system receives data from various sensors and sends it to cloud servers to create big data for elderly health service development, air quality maps with distribution measuring stations, and charging station detection systems in the future. follows:

The contributions of this paper are summarised as

(i) The design of the EPMD is presented in terms of the structure, the electric system, and the sensor system to support usage by the elderly

(ii) The operation of the EPMD for different road surfaces, speeds, and weights is studied and analysed through a real driving test

(iii) The operation of the EPMD system and the air quality detection in the sensor system is presented to display the EPMD status, reduce the caregiver workload, assess the risks of low air quality, and develop the charging station detection system
This research is presented in four sections. In Section 2, the EPMD design is presented in terms of the EPMD structure, the calculation of driving power, the electric equipment, the sensor system, and the overall EPMD. In Section 3, the EPMD is tested by driving on real roads for comparison of different road surfaces, speeds, and total weight. Next, the results of the sensor system are presented to consider the importance of the EPMD status system and the air quality detection system to assess the outdoor activity risks of the elderly. Finally, a summary is presented in Section 4.

\section{Design of Elderly Personal Mobility Device}

The design of the EPMD, a tricycle mobility aid for elderly people in residential areas, is divided into five parts: the structural design, the calculation of propulsion power, the electrical equipment, the design of the sensor system, and the overall EPMD. For the structural design, SolidWorks software was used to simulate the steel chassis. Moreover, the effect of the total weight on the structure, in terms of strain, stress, and displacement, was studied to prevent structural damage caused by carrying the total weight. For the drive power calculation, the total weight obtained from the structural design was used to calculate the motor capacity, while the electric equipment of the EPMD was carefully considered to be compatible with the battery size. Finally, the sensor systems were designed to increase the function and efficiency of the EPMD.

2.1. Structural Design. Various carbon steel shapes, dimensions, and thicknesses were simulated using SolidWorks software in order to design the frame of the EPMD, which must be small and lightweight. The dimensions of the square pipe and rectangular pipe, including the dimensions of the carbon steel, are shown in Table 1 and Figure 1. By considering the shape of the carbon steel pipes in Table 1 and Figure 1(a), it was observed that the case study consisted of $25 \times 25 \mathrm{~mm}^{2}$ carbon steel square pipe, $50 \times 50 \mathrm{~mm}^{2}$ carbon steel square pipe, $25 \times 50 \mathrm{~mm}^{2}$ carbon steel rectangular pipe, and $50 \times 25 \mathrm{~mm}^{2}$ carbon steel rectangular pipe, which were compared in terms of mass, weight, volume, strain, stress, and displacement in order to develop the frame of the vehicle.

By considering the mass, weight, and volume in Table 1, it was found that the $25 \times 25 \mathrm{~mm}^{2}$ carbon steel square pipe was better than the other type of carbon steel pipe, while the $50 \times 50 \mathrm{~mm}^{2}$ carbon steel square pipe was the worst because these parameters correlated with the cross-sectional area. For the next step, the strain displayed in Table 1 and Figure 1(b) was simulated, the specimens were fixed on one end as the fixation point, and the other end was the pressed point at which the force was applied to test the strain on the carbon steel. The results showed that the $50 \times 50 \mathrm{~mm}^{2}$ carbon steel square pipe had the best strain, which has less deformation compared with the other shapes, while the $25 \times 25 \mathrm{~mm}^{2}$ carbon steel square pipe had the worst strain, especially near the fixation point. After simulating the strain, 
TABLE 1: Steel shape comparison results for the carbon steel pipes.

\begin{tabular}{lcccc}
\hline \multirow{2}{*}{ Parameters } & \multicolumn{3}{c}{ Shape of the carbon steel pipes $\left(\mathrm{mm}^{2}\right)$} \\
& $25 \times 25$ & $50 \times 50$ & $25 \times 50$ & 2.251 \\
Mass $(\mathrm{kg})$ & 1.466 & 3.037 & 22.063 & 2.251 \\
Weight $(\mathrm{N})$ & 14.362 & 29.764 & $2.865 \times 10^{-4}$ & 2.063 \\
Volume $\left(\mathrm{m}^{3}\right)$ & $1.865 \times 10^{-4}$ & $3.865 \times 10^{-4}$ & $1.834 \times 10^{-3}$ & $2.865 \times 10^{-4}$ \\
Strain $\left(\mathrm{N} / \mathrm{m}^{2}\right)$ & $2.995 \times 10^{-3}$ & $7.406 \times 10^{-4}$ & $4.972 \times 10^{8}$ & $3.144 \times 10^{-3}$ \\
Stress $\left(\mathrm{N} / \mathrm{m}^{2}\right)$ & $8.423 \times 10^{8}$ & $2.041 \times 10^{8}$ & 54.040 & $17.023 \times 10^{8}$ \\
Displacement $(\mathrm{mm})$ & 95.400 & 10.900 & & 130 \\
\hline
\end{tabular}

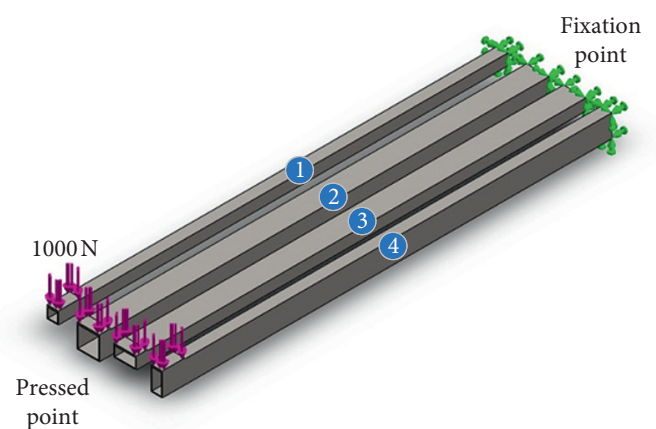

$50 \times 50 \mathrm{~mm}^{2}$ carbon steel square pipe

(2) $25 \times 25 \mathrm{~mm}^{2}$ carbon steel square pipe

(3) $25 \times 50 \mathrm{~mm}^{2}$ carbon steel rectangular pipe

(4) $50 \times 25 \mathrm{~mm}^{2}$ carbon steel rectangular pipe

(a)

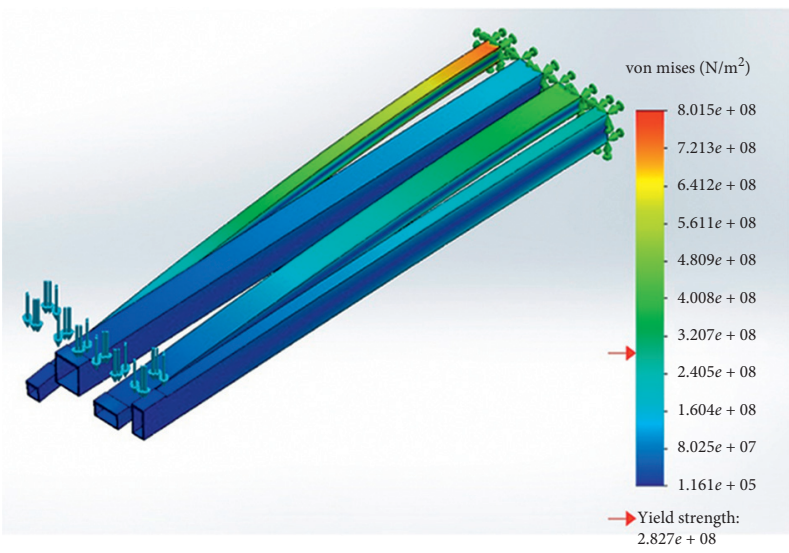

(c)

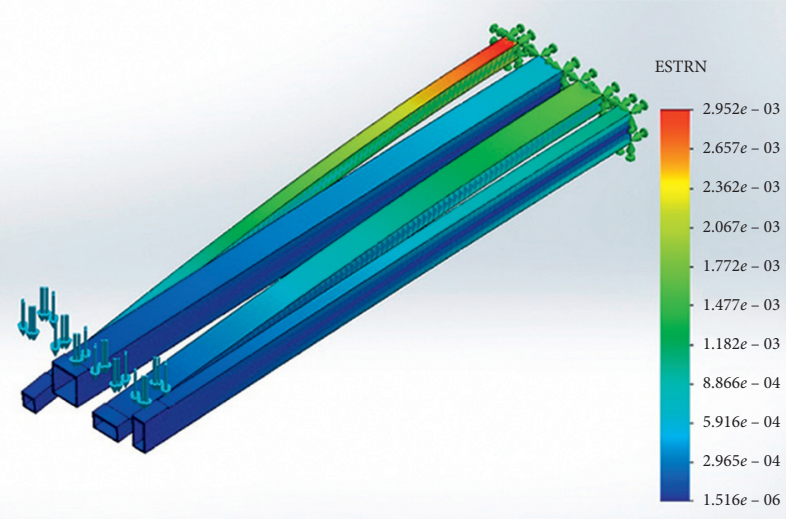

(b)

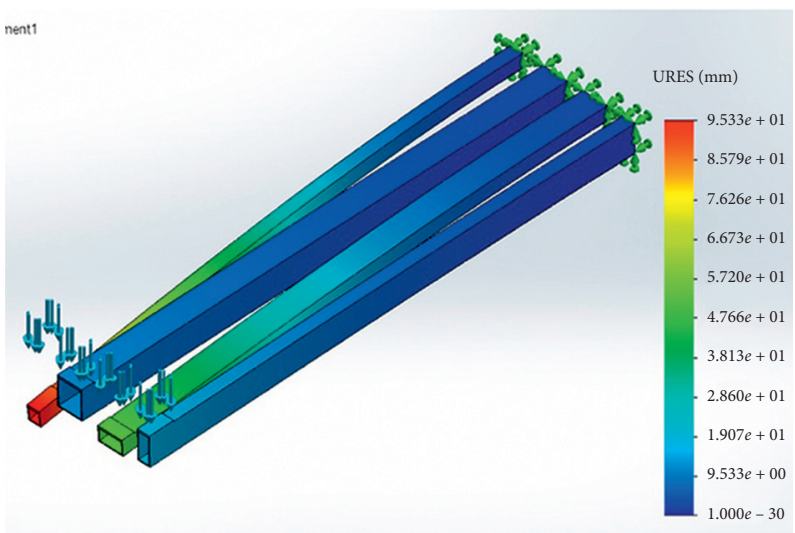

(d)

FIGURE 1: Steel shape comparison results in terms of strain, stress, and displacement. (a) Steel shape comparison of carbon steel pipe. (b) Strain results for the carbon steel pipe. (c) Stress results for the carbon steel pipe. (d) Displacement results for the carbon steel pipe.

the stress and displacement can be achieved at the same time. The obtained results have a similar trend to that of the strain characteristic, as shown in Figure 1(c), Figure 1(d), and Table 1. Further analysis of Table 1 shows that the $25 \times 25 \mathrm{~mm}^{2}$ carbon steel square pipe has the best mass, weight, and volume but has the worst strain, stress, and displacement. This indicates that the $25 \times 25 \mathrm{~mm}^{2}$ carbon steel square pipe is unsuitable for the frame because it cannot support the carried weight. On the other hand, the $50 \times 50 \mathrm{~mm}^{2}$ carbon steel square pipe is also not suitable for designing the vehicle frame due to the weight of the structure, which hinders its usage. Based on a further analysis of Table 1, when considering the mass, weight, and volume, the $25 \times 50 \mathrm{~mm}^{2}$ and $50 \times 25 \mathrm{~mm}^{2}$ carbon steel rectangular pipes have the same values but, by considering the stain, stress, and displacement, the $50 \times 25 \mathrm{~mm}^{2}$ carbon steel rectangular pipe has better characteristics than the other types. This indicates that the $50 \times 25 \mathrm{~mm}^{2}$ carbon steel rectangular pipe is adequate for the vehicle frame.

Based on the previous analysis, the $50 \times 25 \mathrm{~mm}^{2}$ carbon steel rectangular pipe, having adequate mechanical characteristics and low structural weight, was chosen for the 
vehicle frame. The next step is to determine the thickness of carbon steel in terms of mechanical properties and cost analysis. Various thicknesses of the $50 \times 25 \mathrm{~mm}^{2}$ carbon steel rectangular pipe were simulated, and the obtained results are shown in Table 2 and Figure 2. By considering the thicknesses in Table 2 and Figure 2(a), it was observed that the case study consisted of $1.6,2.3$, and $3.2 \mathrm{~mm}$ thicknesses, which were compared in terms of mass, weight, volume, strain, stress, displacement, and total frame price. In addition, the yield strength was also considered when the carbon steel was assembled into a structure, in order to select the frame of the EPMD.

By considering the mass, weight, and volume data in Table 2, it was found that the $1.6 \mathrm{~mm}$ thickness was better than the other thicknesses, while the $3.2 \mathrm{~mm}$ thickness was the worst, due to the larger cross-sectional areas that result in a high mass and volume, which have an adverse impact on the EPMD weight. By considering the strain results obtained from the simulation in Table 2 and Figure 2(b), the frame was fixed on three points as fixation points, i.e., one point at the front axle and two points at rear axle. In addition, three pressed planes, the footrest and the seat of the main frame, and the rear axle support were determined to be testing areas for the mechanical properties of the designed structure. By considering Figure 2(b), the testing force on each plane was set to have weights of $500 \mathrm{~N}, 1000 \mathrm{~N}$, and $500 \mathrm{~N}$ for the footrest, the seat of the main frame, and the rear axle support, respectively. By observing the strain values in Table 2, the $3.2 \mathrm{~mm}$ thickness presented better strain values than the other thicknesses because the higher the thickness, the better the strength, which leads to carbon steel that can withstand the deformations.

The obtained characteristics of stress and displacement are similar to the strain characteristics, as shown in Figure 2(c), Figure 2(d), and Table 2. By considering the yield strength in Figure 2(c), the frame was made of carbon steel, which has a yield strength value of $2.82685 \times 108 \mathrm{~N} / \mathrm{m}^{2}$. If the stress value is higher than the yield strength value, permanent deformation will occur in the vehicle frame. All carbon steel thicknesses illustrate that their yield strength values were within the acceptable range. For this reason, they can be utilised for a vehicle frame. By considering the displacement in Table 2 and Figure 2(d), the displacement value is dependent on the strain and stress values, so that the $3.2 \mathrm{~mm}$ thickness was better than that of the other thickness. The total frame prices are displayed in the bottom row of Table 2. It is observed that the total frame correlates to the volume of the carbon steel; the $1.6 \mathrm{~mm}$ thickness has the most reasonable price of US $\$ 18$ per frame, while the $2.3 \mathrm{~mm}$ and $3.2 \mathrm{~mm}$ thicknesses have prices of $\$ 24$ and $\$ 32$ per frame, respectively. Based on a further analysis of Table 2, when considering the mass, weight, volume, and total frame price, the $1.6 \mathrm{~mm}$ thickness has the best value. Moreover, all thicknesses do not exceed the yield strength limit of the carbon steel rectangular pipe. This indicates that a $1.6 \mathrm{~mm}$ thickness is useful for the vehicle frame in terms of mechanical properties and economic aspects, although the strain and displacement of the $1.6 \mathrm{~mm}$ thickness are less than those of the other thicknesses.
2.2. Calculation of Propulsion Power. Generally, the duration of use and the distance depend on the battery size and the driving power; thus, in this section, the propulsion power is discussed. The propulsion power is a system that converts electrical energy into mechanical energy, which is related to the driving force and the speed of the EPMD. The propulsion power can be calculated from equation (1) $[19,20,33,34]$, where equation (1) is used to calculate the EPMD propulsion power, as summarised in Table 3:

$$
\begin{aligned}
P= & F_{t} V=f_{m} M \alpha_{a} V+M g C_{r r} V \cos \theta \\
& +\frac{1}{2} \rho A C_{d} V\left(V-V_{w}\right)^{2}+M g V \sin \theta .
\end{aligned}
$$

By calculating the size of the motor according to equation (1) and Table 3, the result showed that the required power for the driving force was $448.87 \mathrm{~W}$; thus, a $500 \mathrm{~W}$ Brushless Direct-Current (BLDC) motor was selected for the EPMD, which provides high torque and speed, resulting in smooth and fast acceleration.

2.3. Electrical Equipment. The electrical parameters and positions of the electrical equipment are illustrated in Figure 3 and Table 4. Figure 3(a) shows that the electrical equipment of the proposed EPMD consists of a lithium-ion battery, an EV controller, a headlight, throttles, electric brakes, a forward and reverse switch, a BLDC motor, a monitor display, and an IoT box. As shown in Figure 3(b), the EPMD utilises a lithium-ion battery to supply the electric power for the EV controller, which was installed under the driver's seat, and a BLDC motor, which was installed in the middle of the motor support frame. The EV controller supplies a direct voltage of $48 \mathrm{~V}$ to the headlight, BLDC motor, and monitor display, and a direct voltage of $5 \mathrm{~V}$ to the throttles, electric brakes, and forward and reverse switches. The total power consumption of all electric equipment in the EPMD was the main factor used to select the lithium-ion battery. The mass of the equipment, including the lithiumion battery, impacts the weight of the EPMD design. In addition, the economic feasibility of the vehicle can be determined by the price of each individual component. The specifications of the electric equipment installed in the EPMD in terms of position, voltage, current, power, mass, and price are summarised in Table 4.

As shown in Table 4, a large proportion of power consumption is attributed to the BLDC motor, which heavily influenced the sizing of the battery. Normally, the BLDC motor does not operate at the rated power, and the operating time for an elderly person is approximately 1-2 hours per day, which is limited to small residential areas. The lithiumion battery was designed to store energy for use in driving the EPMD. The battery size was calculated based on the total load power consumption for use within one day, oversized by $20 \%$ to account for battery losses and to avoid the depth of discharge, which causes a decrease in the battery's lifetime. Therefore, the battery capacity required for the proposed EPMD is approximately $624 \mathrm{Wh}$. Hence, a $48-\mathrm{V} 13-\mathrm{Ah}$ lithium-ion battery was chosen. 
TABLE 2: EPMD structural simulation results.

\begin{tabular}{lccc}
\hline Parameters & \multicolumn{3}{c}{ Thickness $(\mathrm{mm})$} \\
& 1.6 & 2.3 & 3.2 \\
\hline Mass $(\mathrm{kg})$ & 19.752 & 27.204 & 36.466 \\
Weight $(\mathrm{N})$ & 193.572 & 266.602 & 357.365 \\
Volume $\left(\mathrm{m}^{3}\right)$ & $2.514 \times 10^{-3}$ & $3.462 \times 10^{-3}$ & $4.641 \times 10^{-3}$ \\
Strain $\left(\mathrm{N} / \mathrm{m}^{2}\right)$ & $1.378 \times 10^{-4}$ & $1.202 \times 10^{-4}$ & $1.343 \times 10^{-4}$ \\
Stress $\left(\mathrm{N} / \mathrm{m}^{2}\right)$ & $1.267 \times 10^{8}$ & $1.109 \times 10^{8}$ & $8.709 \times 10^{7}$ \\
Displacement (mm) & 0.297 & 0.221 & 0.168 \\
Total frame price (USD) & 18 & 24 & 32 \\
\hline
\end{tabular}

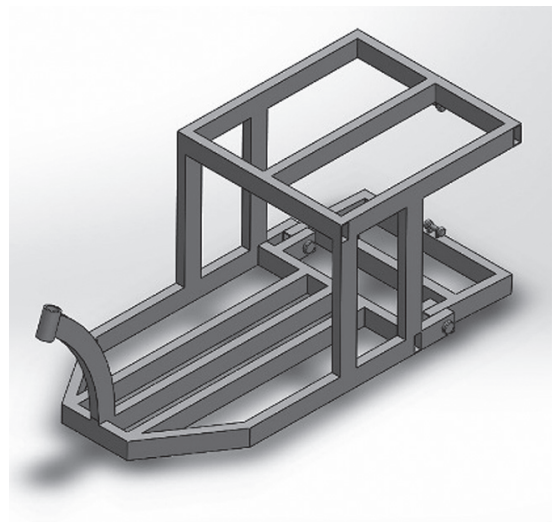

(a)

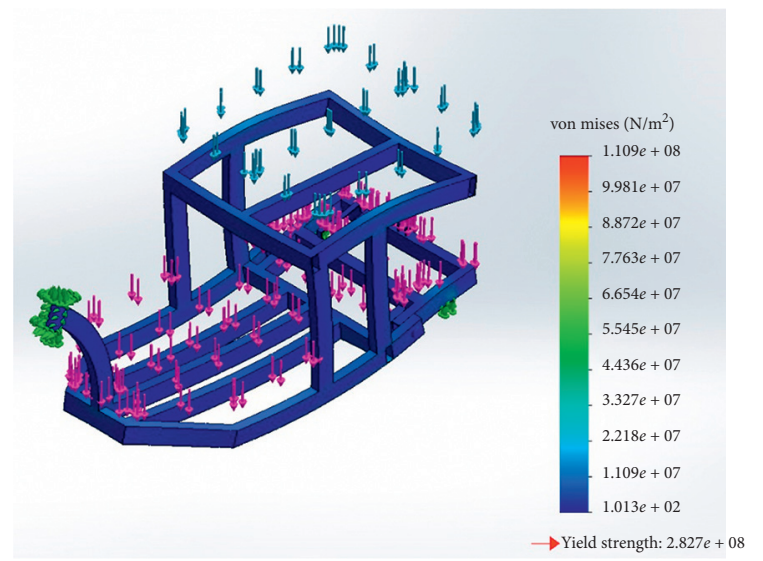

(c)

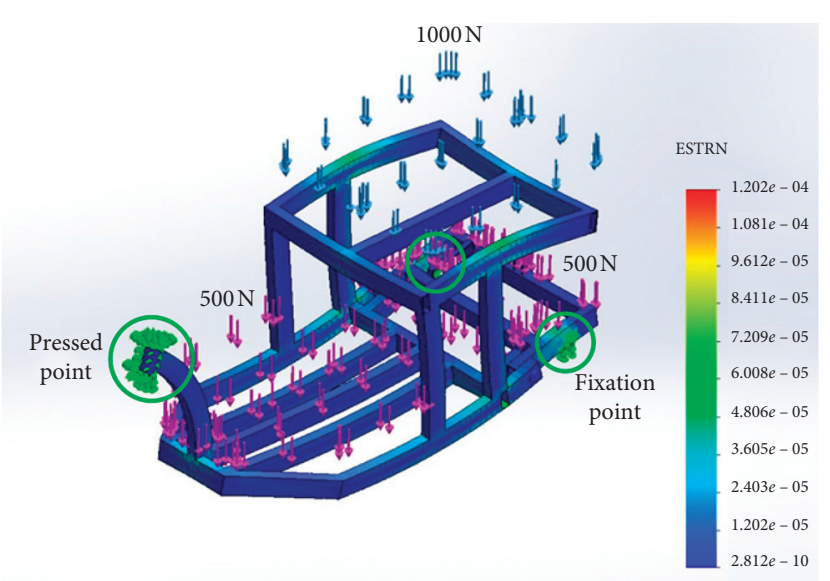

(b)

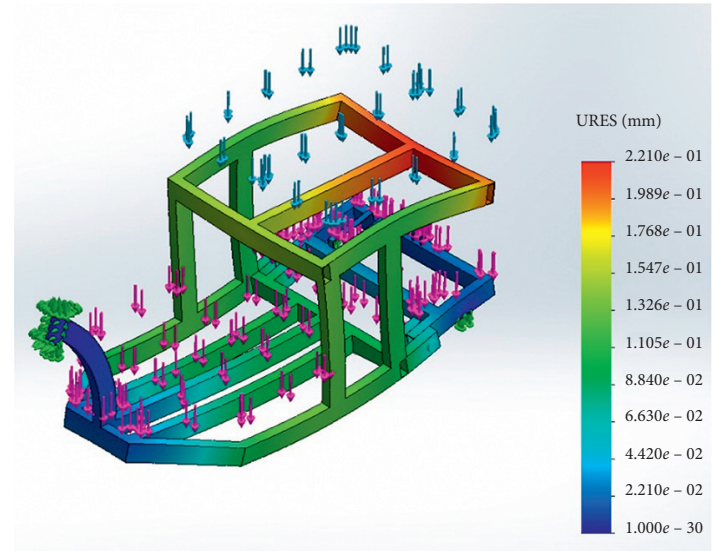

(d)

Figure 2: Simulation results with thickness of $2.3 \mathrm{~mm}$ in terms of strain, stress, and displacement. (a) EPMD frame. (b) Strain results for the EPMD frame. (c) Stress results for the EPMD frame. (d) Displacement results for the EPMD frame.

TABLE 3: The parameters of EPMD propulsion power calculation.

\begin{tabular}{lcc}
\hline The propulsion power calculation parameter & & \\
\hline Total mass $(M)$ & 200 & $\mathrm{~kg}$ \\
Mass factor $\left(f_{m}\right)$ & 1 & - \\
Acceleration $(\alpha)$ & 1 & $\mathrm{~m} / \mathrm{s}^{2}$ \\
Speed $(V)$ & $\mathrm{m} / \mathrm{s}$ \\
Coefficient of rolling resistance $\left(C_{r r}\right)$ & - \\
Gravity $(\mathrm{g})$ & 0.012 & $\mathrm{~m} / \mathrm{s}^{2}$ \\
Air density $(\rho)$ & 9.8 & $\mathrm{~kg} / \mathrm{m}^{3}$ \\
Vehicle frontal area $(A)$ & 1.225 & $\mathrm{~m}^{2}$ \\
Aerodynamic drag coefficient $\left(C_{d}\right)$ & 0.7475 & - \\
Wind speed $\left(V_{w}\right)$ & 0.5 & $\mathrm{~m} / \mathrm{s}$ \\
Road slope angle $(\theta)$ & 0 & $\mathrm{deg}$. \\
Propulsion power $(P)$ & 0 & $\mathrm{~W}$ \\
\hline
\end{tabular}




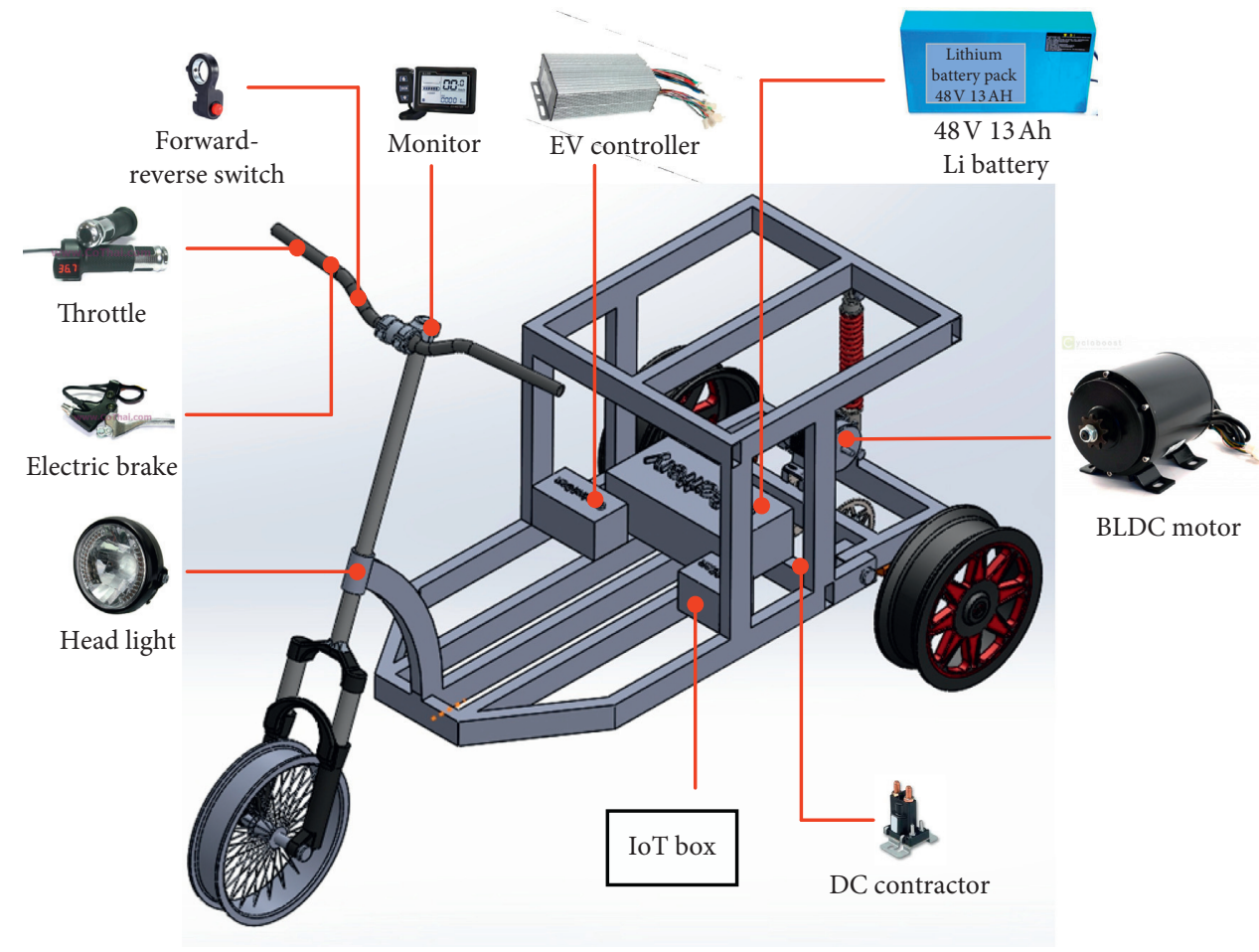

(a)

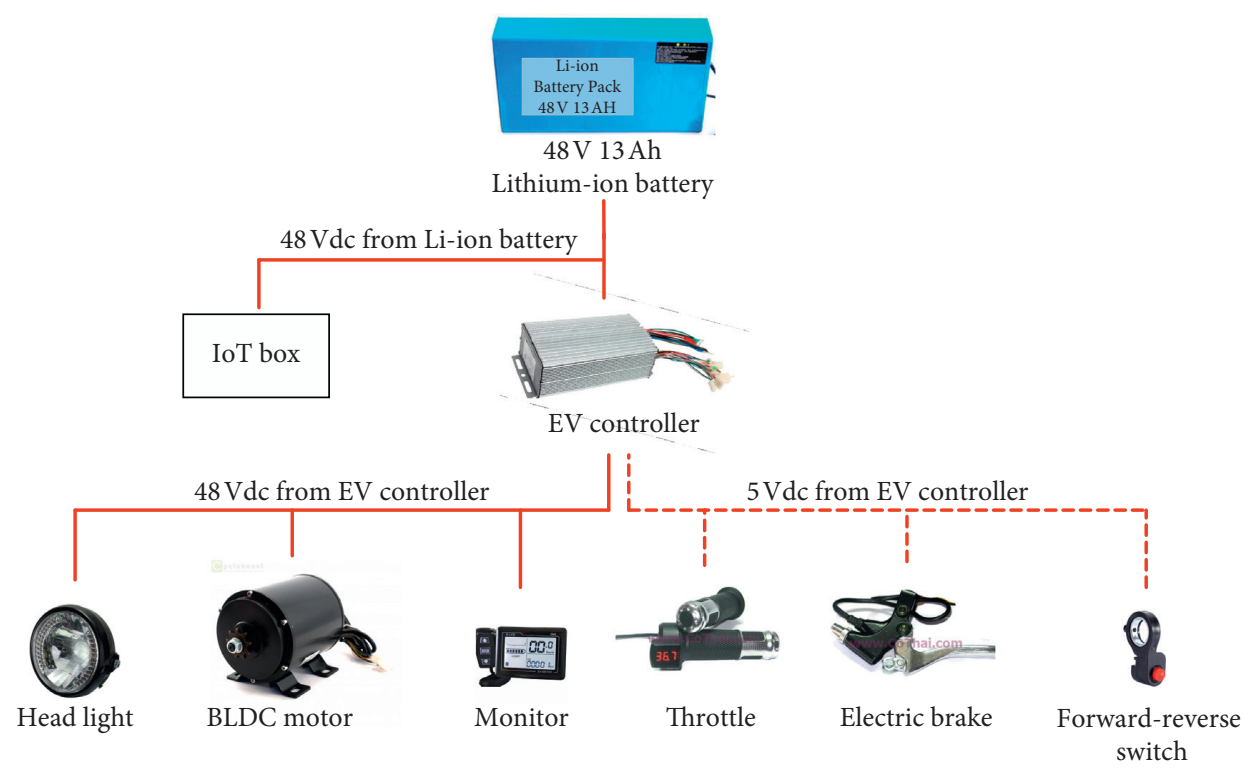

(b)

Figure 3: Electrical equipment in the EPMD. (a) Position of electrical equipment. (b) Schematic diagram of electrical equipment.

Generally, most EVs are standalone devices, which do not communicate or transmit information between other units. Thus, they usually do not have the ability to connect the Internet. However, the proposed EPMD, consisting of the monitoring and notification system, was created to connect among the EPMD, elderly people, caregivers, and elderly families. All users can check the EPMD status, assess the air quality risk, and assist elderly people in emergencies. Therefore, the proposed EPMD will have an IoT box, which is discussed in the next part.
2.4. Design of the Sensor System. Monitoring and notification systems consisting of sensor devices are necessary to reduce the burden of caregivers and to monitor the elderly, as well as to increase the ability and confidence of the EPMD user. The sensor system is designed and assembled in the IoT box, which is used to display and notify the EPMD status, global positioning system (GPS) information, and the air quality status for the EPMD user and caregiver. This system is designed to support real-time operation that is updated every minute and has high accuracy and reliability. In 
TABLE 4: Electrical equipment in the EPMD.

\begin{tabular}{|c|c|c|c|c|c|c|}
\hline \multirow{2}{*}{ Electric equipment } & \multirow{2}{*}{ Position } & \multicolumn{3}{|c|}{ Electrical parameters } & \multirow{2}{*}{ Mass (kg) } & \multirow{2}{*}{ Cost (USD) } \\
\hline & & Voltage (V) & Current (A) & Power $(\mathrm{W})$ & & \\
\hline Head light & Fork frame & 48 & 0.50 & 24 & 0.18 & 18.40 \\
\hline Electric brake & Handle stank & 5 & 0.08 & 0.4 & 0.35 & 20.00 \\
\hline Forward reverse switch & Handle stank & 5 & 0.08 & 0.4 & 0.15 & 6.80 \\
\hline Monitor & Handle connecting & 48 & 0.02 & 0.96 & 0.30 & 25.00 \\
\hline Throttle & Handle stank & 5 & 0.12 & 0.6 & 0.35 & 16.70 \\
\hline EV controller & Main EV frame & 48 & 0.02 & 0.96 & 0.55 & 83.40 \\
\hline BLDC motor & Rear axle support & 48 & 10.42 & 500 & 5.08 & 126.70 \\
\hline IoT box & Main EV frame & 48 & 0.02 & 0.96 & 0.32 & 183.40 \\
\hline \multicolumn{2}{|c|}{ Total load } & 48 & 11.01 & 528.28 & 7.28 & 480.40 \\
\hline Lithium-ion battery & Main EV frame & 48 & 13 & 624 & 7.00 & 400.00 \\
\hline
\end{tabular}

addition, the system also contains the $4 \mathrm{G}$ Wi-Fi router used for transferring the data of the EPMD status and the air quality detection to the user via an Internet connection, as shown in Figure 4. A lithium-ion battery is used to supply power to the IoT box, ESP32 microcontrollers (Espressif Systems, China), and 4G Wi-Fi router, through LM2596HV step-down converters. The first converter steps down the voltage from $48 \mathrm{~V}$ to $5 \mathrm{~V}$ and sends it to the ESP32 microcontrollers, including the EPMD status board and the air quality board. Another converter is used to step down the voltage level from $48 \mathrm{~V}$ to $12 \mathrm{~V}$ for supplying power to the $4 \mathrm{G}$ $\mathrm{Wi}-\mathrm{Fi}$ router. The voltage sensor, GPS sensor, and emergency switch in the EPMD status board are used to collect data of the battery voltage, locations of elderly people, EPMD locations, and emergency status, respectively. For the air quality status board, particulate matter (PM), carbon dioxide $\left(\mathrm{CO}_{2}\right)$, and humidity and temperature sensors are utilised to detect the PM in air, $\mathrm{CO}_{2}$, humidity, and temperature around the EPMD.

2.4.1. EPMD Status System. The EPMD status system is important for tracking the EPMD usage status, notifying emergency events, and locating elderly people, and the EPMD based on using different sensors, emergency switches, voltage sensors, and GPS sensors, as shown in Figure 5(a). By considering the operation flow in Figure 5(b), the system operation was implemented when the Blynk and $\mathrm{Wi}$-Fi were properly connected to the ESP32 board. In the next step, the system checks the status of the emergency switch. If the emergency switch is pressed, the system will notify the emergency status to the caregiver via the Blynk and Line applications. The system will hold the emergency state for $20 \mathrm{~s}$ and then restart the system. On the other hand, if the emergency switch is not pressed, the emergency status is normal and skips to the next step. The battery terminal voltage is measured by a voltage sensor to evaluate the remaining battery capacity. When the remaining battery capacity is less than $20 \%$, the system will alert via the EPMD user and caregiver via the Blynk and Line applications. Likewise, the GPS of the EPMD is used to calculate the distance between the EPMD and the nearest charging station [35]. The system will show a list of the available charging stations around the EPMD areas to support elderly decisions in unexpected situations caused by an out-of-charge battery during the use of the EPMD.

The location of the elderly people and the EPMD are shown in the Blynk application. For the location of the elderly people, the Blynk application receives latitude and longitude data from an elderly person's smartphone, which is sent to the ESP32 board every $30 \mathrm{~s}$. For the EPMD location, the board reads the latitude and longitude data from a NEO6 M V2 GPS sensor installed in the EPMD. Next, the location data are shown in the Google map widget in the Blynk application. The accumulated data (emergency status, battery voltage, elderly position, and EPMD position) are recorded in the Google Cloud platform database in the spreadsheet section. This data are automatically recorded every minute, to be used as a database for further development of the EPMD in the future.

2.4.2. Air Quality Detection System. The air quality detection system utilises a particulate matter sensor (PMS 3003, Plantower Technology, China), a digital humidity and temperature sensor (DHT11, Aosong Electronics Co., China), and an intelligent infrared carbon dioxide module (MH-Z14A, Winsen Electronics Technology Co., China) to detect PM, temperature, humidity, and $\mathrm{CO}_{2}$, as shown in Figure 6(a). By considering the operation flowchart in Figure 6(b), the air quality detection system starts by detecting the Blynk and Wi-Fi connection. Next, the ESP32 board receives the PM data from the PMS 3003 sensor and then separates the data according to the PM diameters: $0.3-1.0 \mu \mathrm{m}$ (PM1), 1.0-2.5 $\mu \mathrm{m}$ (PM2.5), and $2.5-10 \mu \mathrm{m}$ (PM10). The obtained data were collected in units of micrograms per cubic metre $\left(\mu \mathrm{g} / \mathrm{m}^{3}\right)$, then converted into the Air Quality Index (AQI) [26], and sent to the Blynk application to assess the risk of elderly health impact based on the air quality in the area. The temperature and humidity in the air were measured by the DHT11 sensor, converted into digital signals, and sent to the ESP32 board. The system sends temperature and humidity values to the Blynk application. The $\mathrm{CO}_{2}$ density is measured by the $\mathrm{MH}-\mathrm{Z} 14 \mathrm{~A}$ sensor, which gives a value in parts-per-million ( $\mathrm{ppm})$. The $\mathrm{CO}_{2}$ value is sent to the Blynk application and compared to the standard of the American Society of Heating, Refrigerating, and Air-Conditioning Engineers (ASHRAE) [36] for 


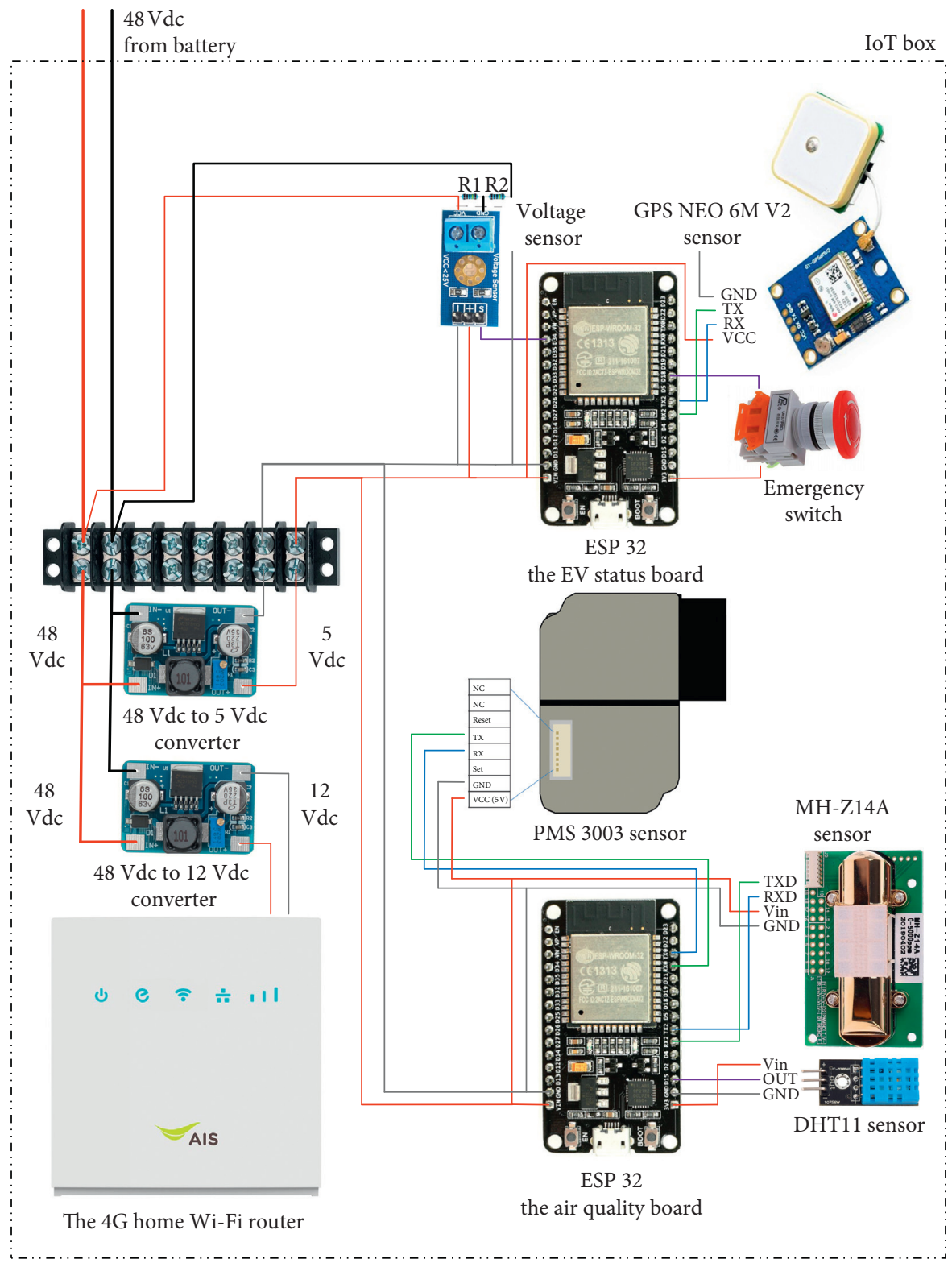

FIGURE 4: Monitoring and notification systems in the IoT box.

elderly health impact evaluation. Finally, the PM, AQI, temperature, humidity, and $\mathrm{CO}_{2}$ data are automatically recorded in the database on the Google Cloud platform in spreadsheets, which is used as air quality data for a given area.

2.4.3. Data Transmission System. The overall proposed IoT system used in the EPMD is depicted in Figure 7, which consists of the EPMD status board and the air quality board. Both boards receive and process data from various sensors installed in the EPMD. Subsequently, the processed data are sent to the $4 \mathrm{G}$ Wi-Fi router, which is connected using cloud computing via the $4 \mathrm{G}$ wireless communication system. This has great benefits for sensor systems, data transfer, and EPMD development in the future. The data are recorded in the three applications on cloud servers, including Blynk,
LINE Notify, and Google Cloud, and the results are shown via application interfaces. Therefore, the EPMD user and caregivers can observe real-time information, notification, and historical data via smartphone applications. In addition, they can also analyse the usage from the database in the cloud server, which is convenient for monitoring the EPMD status and health risk assessment for highly effective elderly care.

2.5. Overall Specifications of the EPMD. As shown in Figures $8(\mathrm{a})$ and $8(\mathrm{~b})$, the designed dimensions of the EPMD are $140 \times 65 \times 115 \mathrm{~cm}^{3}$ (length $\times$ width $\times$ height), which is suitable for comfort, safety, ease of ingress and egress, and ease of propulsion. As shown in Figure 8(c), a handle stank, a handle connector, a fork frame, and a front wheel rim (indicated by numbers 1,2,3, and 4) are utilised to support 


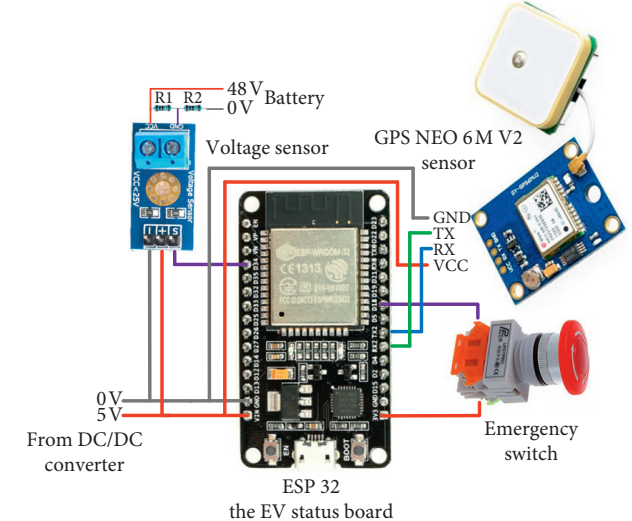

(a)

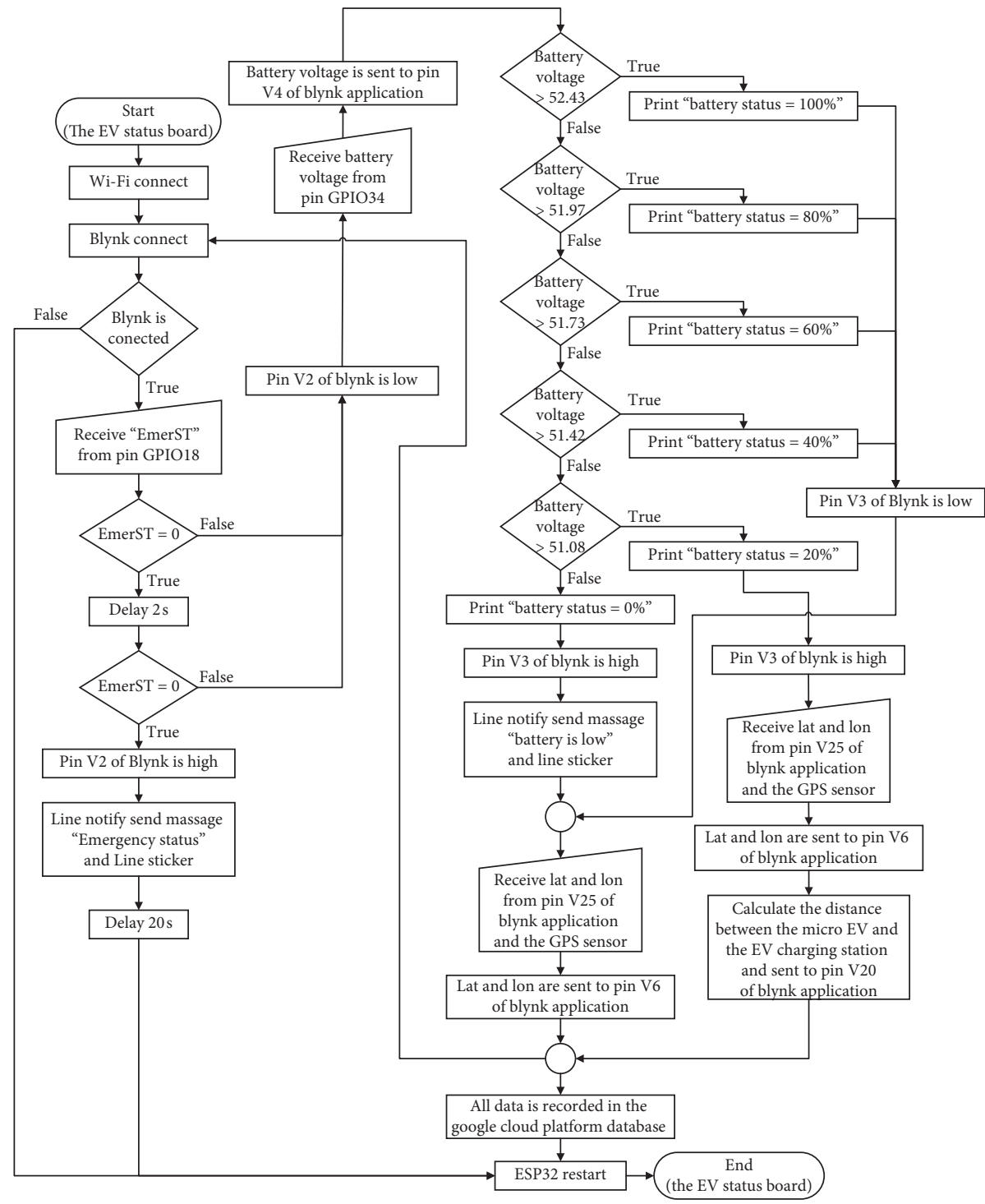

(b)

Figure 5: EPMD status system. (a) EPMD status system diagram. (b) Operating flowchart of EPMD status system.

the weight of the front and control the direction of the EPMD's movement. A carbon steel rectangular pipe is used as the main structure (indicated by number 5 ) and the rear axle support (indicated by number 6), which can support a force up to $2000 \mathrm{~N}$ and consists of the structure, electric and electronic equipment, BLDC motors, batteries, and loading 


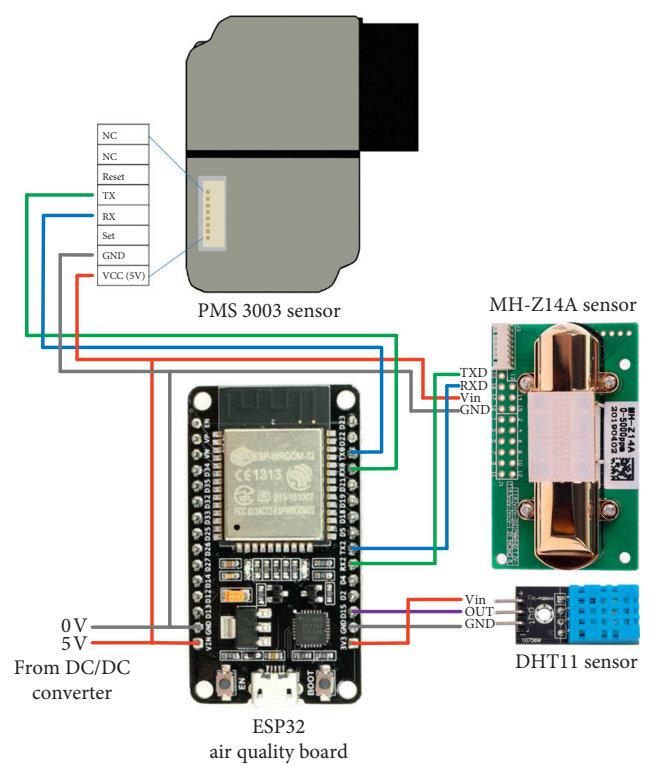

(a)

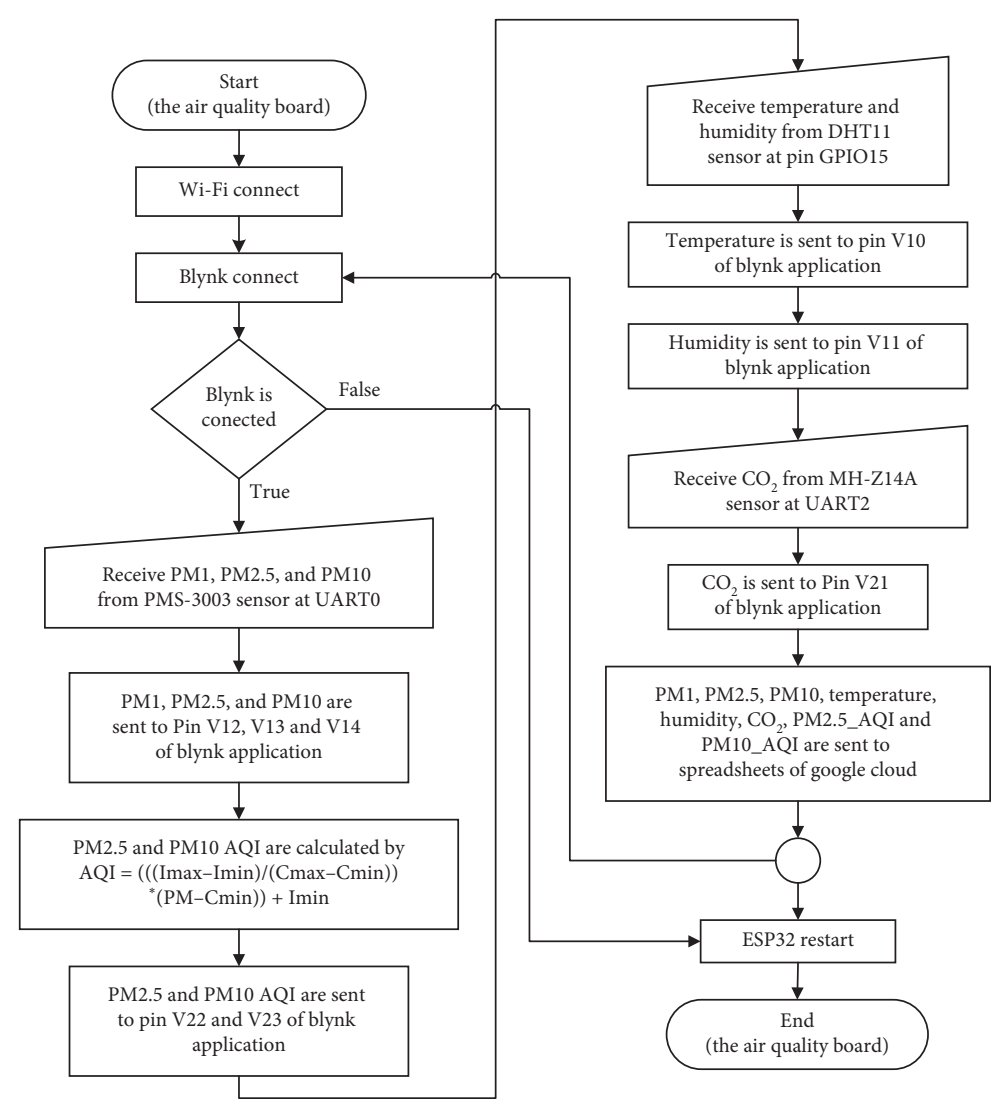

(b)

FIGURE 6: Air quality detection system. (a) Air quality detection diagram. (b) Operating flowchart for air quality detection system.

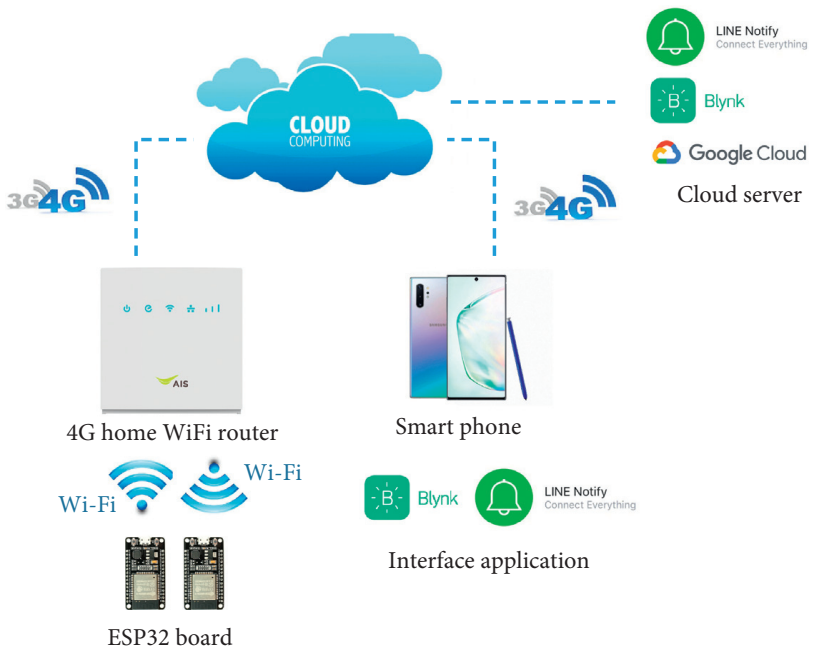

Figure 7: Data transmission system.

weights (driver and carried weights). In addition, to improve the ride quality and vehicle handling for elderly people during driving, a 330- $\mathrm{mm}$ shock absorber (indicated by number 7) is used to absorb the vibration. The rear axle and rear wheel (indicated by numbers 8 and 9) are attached to the rear axle support with a pedestal bearing (indicated by number 10) as the main part of the electric vehicle driving. For the drive system, a BLDC motor (indicated by number
11) is used as a central motor to spin the chain, which transmits the force to the chain gear (indicated by number 12) mounted on the rear axle to drive the EPMD. The BLDC motor is powered by a lithium-ion battery (indicated by number 13) via the EV controller (indicated by number 14), which is used to adjust the speed of the EPMD depending on the driving needs. For the EPMD brake, the electric brake is connected to the control box to cut off the power of the motor, while the oil brake is connected to the disc brake (indicated by number 15), which is mounted on the rear axle, to slow down the EPMD. Finally, the IoT box (indicated by number 16), comprising the monitor and notification systems, is designed to increase the efficiency and usability of the EPMD.

The EPMD was built according to the above design as a three-wheel EV powered by the BLDC motor, as shown in Figure 9. The EPMD can actually run on the roads of a university, which has several road conditions: smooth roads, rough roads, steep slopes, etc. The speed range can be between 0 and $30 \mathrm{~km} / \mathrm{h}$, and the designed structure can bear a weight up to $2000 \mathrm{~N}$. In addition, the vehicle's sensor system is able to effectively respond to the proposed functions of monitoring and notifying.

The results of the EPMD test are presented in the next section based on the differences in road conditions, velocities, and total weights. In order to analyse the EPMD performance, the parameters of battery voltage and total 

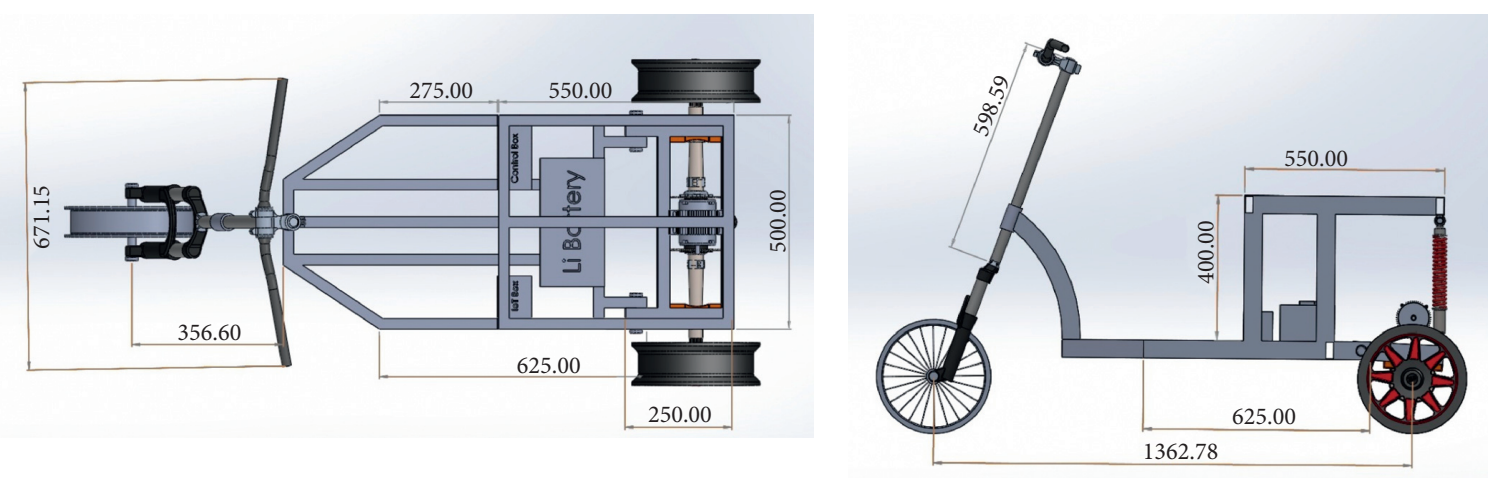

(a)

(b)

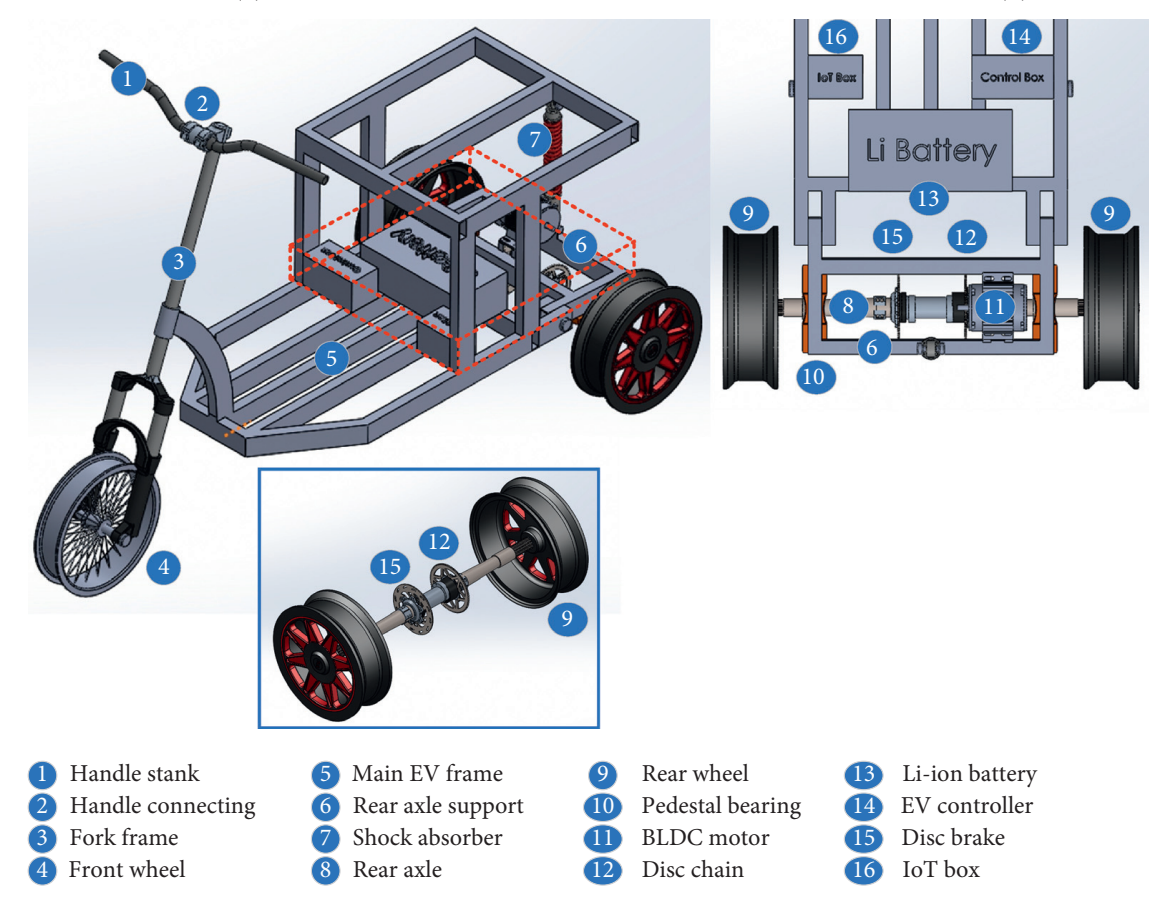

(c)

Figure 8: EPMD dimensions and structure. (a) Top view dimensions. (b) Side view dimensions. (c) EPMD structure.

operating time were used. In addition, the monitor and notification of the sensor system are detailed in Section 3 to describe screen patterns, notification format, and interaction with the obtained results.

\section{Test Results of the Elderly Personal Mobility Device}

The EPMD was built and tested at a university with a wide variety of testing conditions and measurement tools. By considering equation (1) in Section 2, it was observed that the important variables that affect the propulsion power are total weight, speed, acceleration, and road surface. In this case study, the EPMD test was set to have 12 cases, which reflect the differences of the road surfaces, speeds, and weights, as shown in Table 5. For the differences between road surfaces, i.e., smooth (cement road type) and rough (gravel road type), road surfaces were studied to observe the battery voltage level and total operating time of the EPMD with various total weights.
The total weight is the sum of the EPMD's weight, which is approximately $70 \mathrm{~kg}$, and the driver's weights, which are 50, 70, and $90 \mathrm{~kg}$. The obtained results are explained in Section 3.1. Speeds of 5,15 , and $25 \mathrm{~km} / \mathrm{h}$ with various total weights were tested on the smooth road surface; the obtained results are explained in Section 3.2. Next, the EPMD was compared with a commercial elderly EV to determine the performance of applications that could meet the needs of the elderly. The performance was determined while operating and charging the battery, as explained in Section 3.3. Finally, the design and test results of the proposed sensor system for supporting travel, monitoring the EPMD status and air quality, locating the elderly people, and notifying in emergencies are described in Section 3.4 .

3.1. Comparison of the EPMD Driving Effects on Different Road Surfaces. The EPMD was tested using smooth and rough road surfaces to study the effects of the battery voltage and 


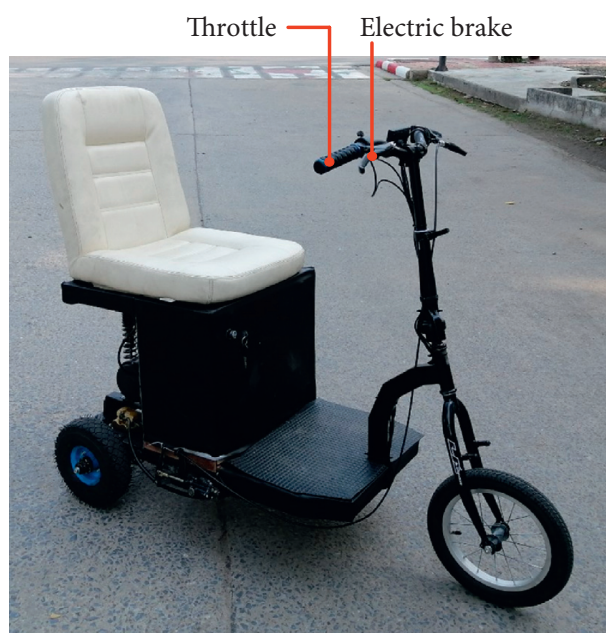

(a)

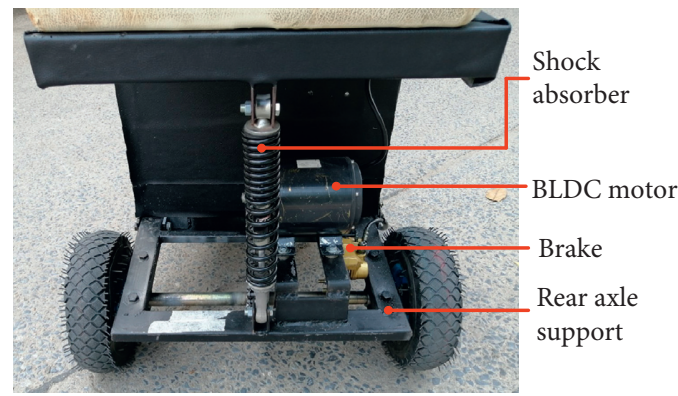

(c)

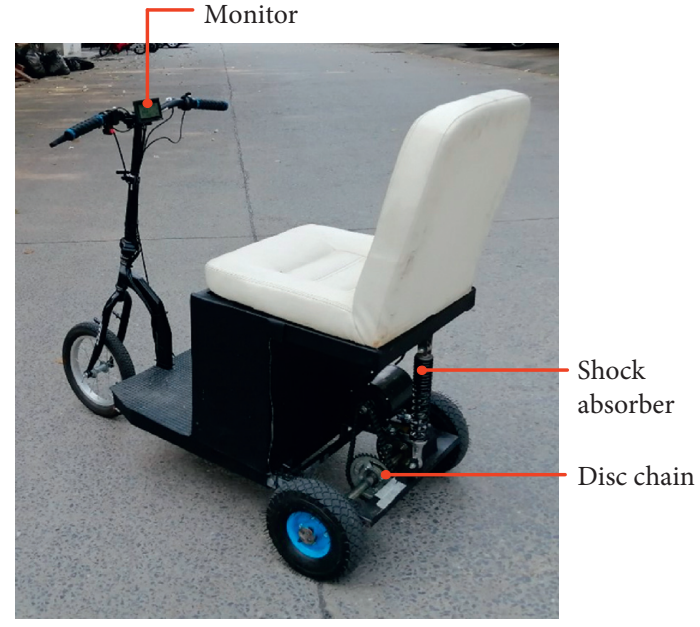

(b)

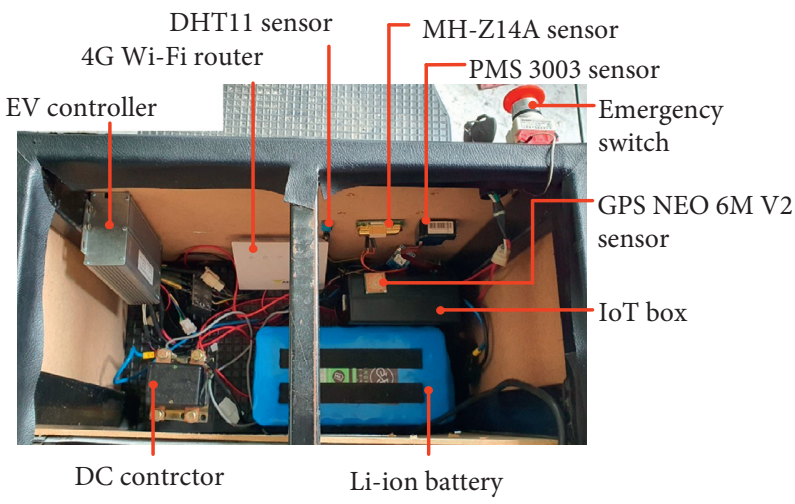

(d)

Figure 9: EPMD components. (a) The frontward isometric view. (b) The backward isometric view. (c) EPMD rear axle support structure. (d) Electrical equipment of the EPMD.

TABLE 5: EPMD test cases.

\begin{tabular}{lccc}
\hline Case & Road surface & Total weight $(\mathrm{kg})$ & Speed $(\mathrm{km} / \mathrm{h})$ \\
\hline 1 & Smooth & 120 & 5 \\
2 & Smooth & 120 & 15 \\
3 & Smooth & 120 & 25 \\
4 & Smooth & 140 & 5 \\
5 & Smooth & 140 & 15 \\
6 & Smooth & 140 & 25 \\
7 & Smooth & 160 & 5 \\
8 & Smooth & 160 & 15 \\
9 & Smooth & 160 & 25 \\
10 & Rough & 120 & 5 \\
11 & Rough & 140 & 5 \\
12 & Rough & 160 & 5 \\
\hline
\end{tabular}

total operating time, as shown in Figure 10. Due to the driving speed limitation in residential areas and the safety of the users while driving on both road surface conditions, the tested speed was set to $5 \mathrm{~km} / \mathrm{h}$. For total weights of 120,140 , and $160 \mathrm{~kg}$, results were obtained using a Fluke 435-II Power Quality and Energy Analyzer. The obtained results of the battery voltage and total operating time for both road surfaces are presented in Figure 11.
The case of a total weight of $120 \mathrm{~kg}$ is presented in Figure 11(a). The results show that the battery voltages of both road surfaces constantly decrease according to the period of use. However, the reduction rate of the battery voltage on the rough road is higher than that on the smooth road with a low battery. In addition, on the rough road surface, the EPMD needs more propulsion power to drive, which results in a greater consumption of current and voltage, causing voltage fluctuations. The result, described in the form of equation (1) as the rolling resistance coefficient, directly affects the propulsion power; for the smooth road surface and the rough road surface, the rolling resistance coefficients are 0.012 and 0.020 , respectively. By considering the total operating time, the case of a smooth road surface is 242 min with a distance of $20.17 \mathrm{~km}$, while the case of a rough road surface is $214 \mathrm{~min}$ with a distance of $17.83 \mathrm{~km}$. Results for the cases of total weights of 140 and $160 \mathrm{~kg}$ are shown in Figures 11(b) and 11(c), respectively. By considering only the road surfaces, the behaviour of the battery voltage and total operating time are similar for the case of $120 \mathrm{~kg}$; however, when the weight increases, the total operating time tends to decrease. 


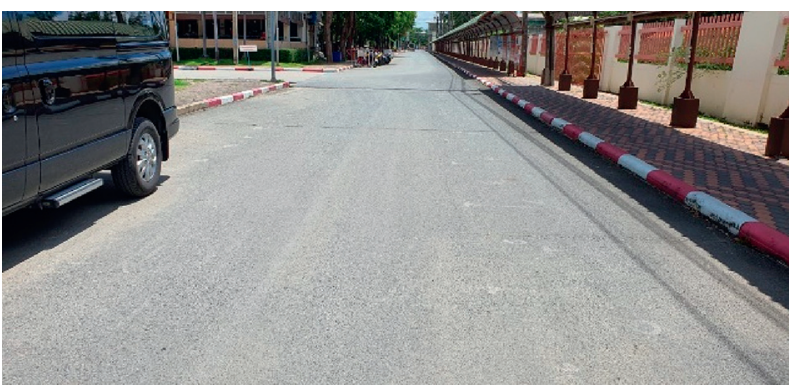

(a)

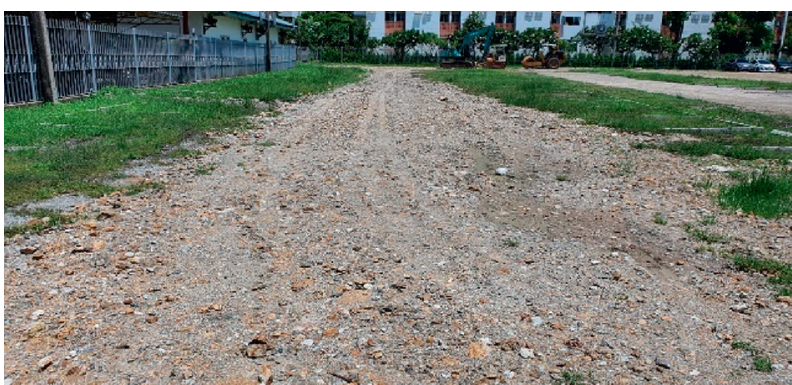

(b)

FIGURE 10: Road surface conditions used in case studies. (a) Smooth road (cement road type). (b) Rough road (gravel road type).

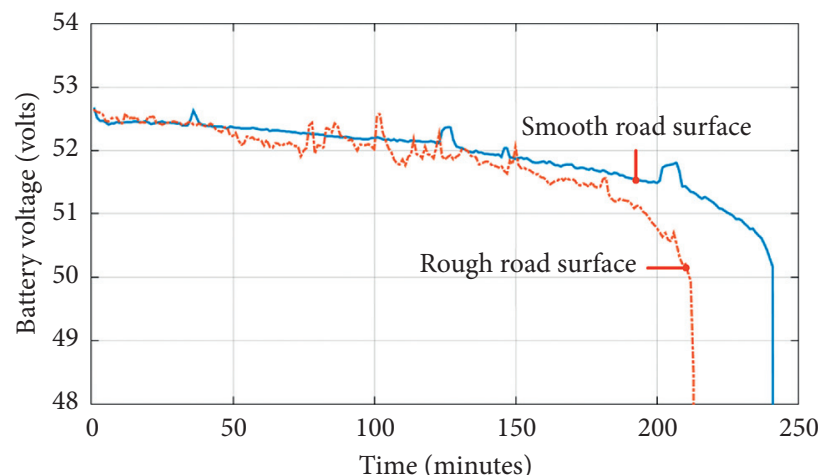

— Smooth road with $5 \mathrm{~km} / \mathrm{hr}(120 \mathrm{~kg})$

...- Rough road with $5 \mathrm{~km} / \mathrm{hr}(120 \mathrm{~kg})$

(a)

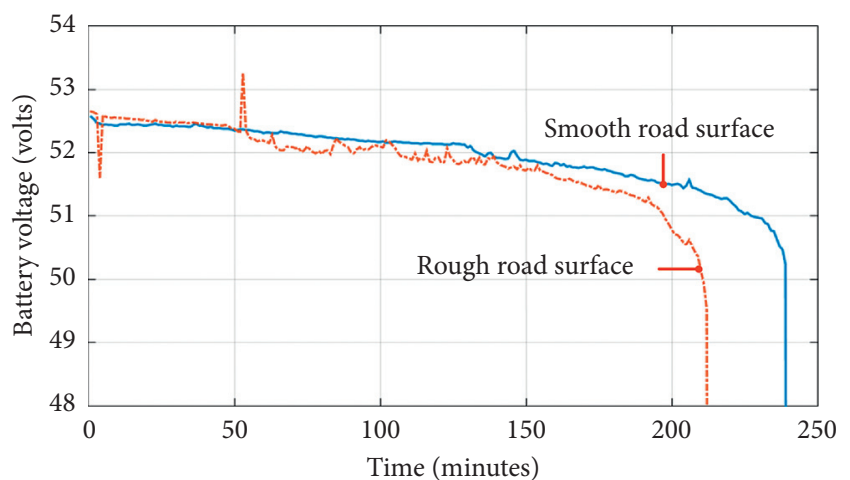

— Smooth road with $5 \mathrm{~km} / \mathrm{hr}(140 \mathrm{~kg})$ ...- Rough road with $5 \mathrm{~km} / \mathrm{hr}(140 \mathrm{~kg})$

(b)

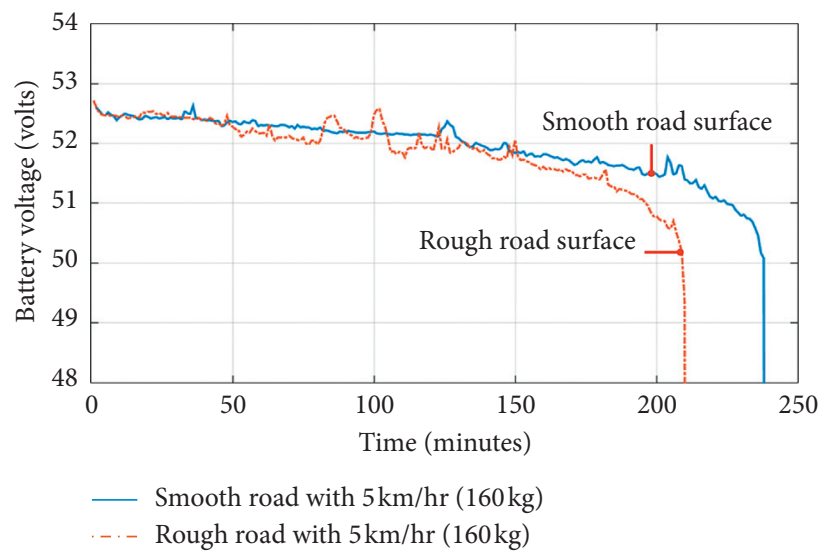

(c)

Figure 11: The obtained results of the different road surfaces with each total weight. (a) $120 \mathrm{~kg}$. (b) $140 \mathrm{~kg}$. (c) $160 \mathrm{~kg}$.

By increasing the weight and not changing the road surfaces, the EPMD requires more propulsion power, which results in reduced operating time. For this reason, the total weight of the propulsion power in equation (1) is taken into consideration. The total operating time for the smooth road surface in cases with total weights of 140 and $160 \mathrm{~kg}$ is 240 and $239 \mathrm{~min}$, which correspond to distances of 20 and $19.92 \mathrm{~km}$, respectively, while the rough road surface results in total operating times of 213 and $211 \mathrm{~min}$, which correspond to distances of 17.75 and $17.58 \mathrm{~km}$, respectively.
In summary, by changing the road surfaces and not the speed, the case of the rough road surface with all total weights provides higher voltage fluctuations and lower total operating time compared with the smooth road surface. The obtained distances for the smooth road surface are higher than for the rough road surface by approximately $11.57 \%$. This indicates that an estimation of the distance of EPMD operation can benefit from an analysis of the road surface. By changing the total weight and not the speed, the operating time tends to decrease when the total weight is increased. 
3.2. Comparison of EPMD Driving at Different Speeds. It has been shown that the EPMD can be driven on both smooth and rough road surfaces. The distance is approximately $20 \mathrm{~km} /$ charge, which is suitable for use in residential areas. Most residential areas have a smooth road and shared road users, so that speed is another factor affecting driver safety. Generally, in residential areas, the speed is in the range of $15-25 \mathrm{~km} / \mathrm{h}$; thus, in this test, the EPMD was tested with various speed adjustments. The EPMD was tested at speeds of 5,15 , and $25 \mathrm{~km} / \mathrm{h}$ with various total weights. The results of the battery voltage and total operating time for each total weight are shown in Figure 12.

In Figure 12(a), the EPMD with a total weight of $120 \mathrm{~kg}$ is considered, and the battery voltage decreases with respect to the period of use. When the EPMD is driven at high speed, it requires more propulsion power, resulting in greater consumption of current and voltage and causing voltage fluctuations and low operating times. For speeds of 5, 15, and $25 \mathrm{~km} / \mathrm{h}$, the total operating times are 242,118 , and $73 \mathrm{~min}$, which correspond to distances of $20.17,29.50$, and $30.42 \mathrm{~km}$, respectively.

As shown in Figures 12(b) and 12(c), the total weights of 140 and $160 \mathrm{~kg}$ have battery voltage reductions and total operating times similar to those for a total weight of $120 \mathrm{~kg}$ when the testing speed is varied. However, according to equation (1), the total weight of the EPMD has a direct effect on the total operating time. A total weight of $160 \mathrm{~kg}$ results in the lowest operating time when compared to the other weights at the same speed. For a total weight of $140 \mathrm{~kg}$ at speeds of 5,15 , and $25 \mathrm{~km} / \mathrm{h}$, the total operating times are 240,117 , and $70 \mathrm{~min}$, corresponding to distances of 20 , 29.25 , and $29.17 \mathrm{~km}$, respectively. For a total weight of $160 \mathrm{~kg}$, at speeds of 5,15 , and $25 \mathrm{~km} / \mathrm{h}$, the total operating times are 239,115 , and $68 \mathrm{~min}$, with corresponding distances of $19.92,28.75$, and $28.33 \mathrm{~km}$.

Next, the distances obtained at the tested speeds are considered. Although the lowest speed offers the best total operating time, it does not provide the longest distance. For example, the EPMD weight of $120 \mathrm{~kg}$ tested at a speed of $5 \mathrm{~km} / \mathrm{h}$ has the best total operating time, while the distance is approximately $20 \mathrm{~km}$. Speeds of 15 and $25 \mathrm{~km} / \mathrm{h}$ result in lower total operating times but result in a distance of approximately $30 \mathrm{~km}$, which is greater than that obtained for a speed of $5 \mathrm{~km} / \mathrm{h}$.

\subsection{Comparison of the EPMD with a Commercial Elderly EV.} It has been shown that the EPMD can be driven on several road surfaces at various speeds and weights, which provide a range of distances that cover the daily use of elderly people. By considering the efficiency of the EPMD in response to its use by elderly people, the EPMD is compared with a commercial elderly EV, as shown in Figure 13. For this comparison, the motor size and battery capacity of the commercial elderly EV, which are close to those of the EPMD, were selected to be able to directly compare their operation, as shown in Table 6. The commercial elderly EV uses two 250-W gear motors to drive the left and right wheels separately. The motors efficiently transmit power to the wheels directly, but they create a strong jolt while starting. A 480 -Wh lithium-ion battery is used, which is sufficient to power the motor. In addition, a common charger is used, which has a charging time of up to $7.41 \mathrm{~h}$. For the EPMD, the 500-W BLDC motor is used to transmit power through the chain to spin the rear axle, which can reduce the jolt while starting. A $625 \mathrm{Wh}$ lithium-ion battery and a fast charger are used, which can shorten the charging time to $2.89 \mathrm{~h}$. Although the battery capacity of the EPMD is higher than that of the commercial elderly EV, the charging time of the EPMD is lower, because the EPMD uses a fast charger that supplies dc power of $48 \mathrm{~V}, 5 \mathrm{Ah}, 240 \mathrm{Wh}$; while the commercial elderly EV uses a 24-V 3-Ah 72-Wh charger. In addition, the commercial elderly EV has a lower weight than the EPMD because the commercial elderly EV has a lightweight aluminium frame. However, the aluminium frame has a limitation in the carry load of no more than $100 \mathrm{~kg}$. On the other hand, the EPMD is made has a carbon steel frame, which provides great strength but is relatively heavy. The EPMD frame can support outdoor use and a load of up to $200 \mathrm{~kg}$.

Next, the speed, operating time, and distance are compared. The commercial elderly EV has a maximum speed of $5 \mathrm{~km} / \mathrm{h}$ with a distance of $24.92 \mathrm{~km} /$ charge, which is not suitable for outdoor use, while the proposed EPMD has a maximum speed of $25 \mathrm{~km} / \mathrm{h}$ with a distance of $30.42 \mathrm{~km} /$ charge (the distance is $19.92 \mathrm{~km} /$ charge for a speed of $5 \mathrm{~km} / \mathrm{h}$ ), which is a controllable speed for elderly people and is suitable for use within residential areas. If both EPMD and commercial elderly EV are driven at a speed of $5 \mathrm{~km} / \mathrm{h}$, the distance of the EPMD is less than that of the commercial elderly EV because the BLDC motor efficiency decreases when the EPMD speed decreases, and the EV weight of the EPMD is greater than that of the commercial elderly EV of $25 \mathrm{~kg}$. In terms of cost, it was determined that the cost of the EPMD is higher than that of the commercial elderly EVs because it is still a prototype. If it is developed on a larger scale, the production costs will be reduced. In addition, the EPMD can also be driven at higher speeds, achieve greater distances, and charge faster. Although the EPMD has a higher weight, it can support a $200 \mathrm{~kg}$ payload and has a sensor system that is not available in the commercial elderly EV. The sensor system can help the elderly to assess travel health risks and alert caregivers in the event of an emergency. Therefore, the EPMD is more cost-effective and able to meet the needs of elderly people, caregivers, and elderly families.

3.4. Results for the Sensor System. The sensor system is designed to monitor the EPMD status, air quality, elderly people, and EPMD location. All information is sent to the mobile application on the smartphones of the users, caregivers, and elderly families. LINE Notify, Google Cloud, and Blynk servers were used as the data storage servers of the system. LINE Notify is used to alert the occurrence of an emergency. Google Cloud accumulates all information as a database in terms of the data logger for future system 


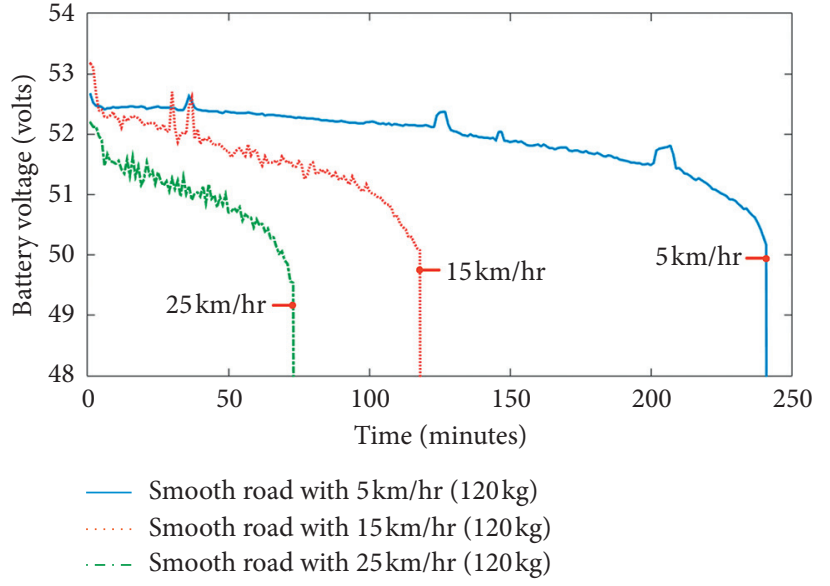

(a)

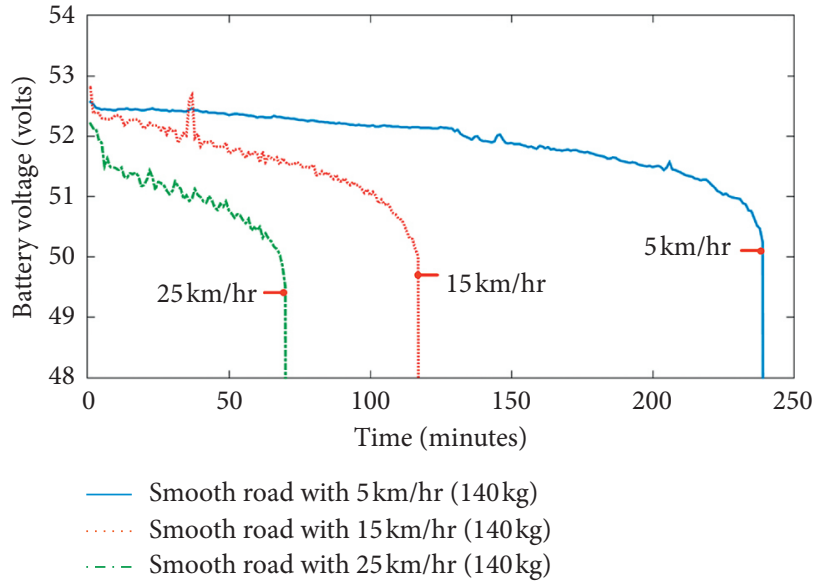

(b)

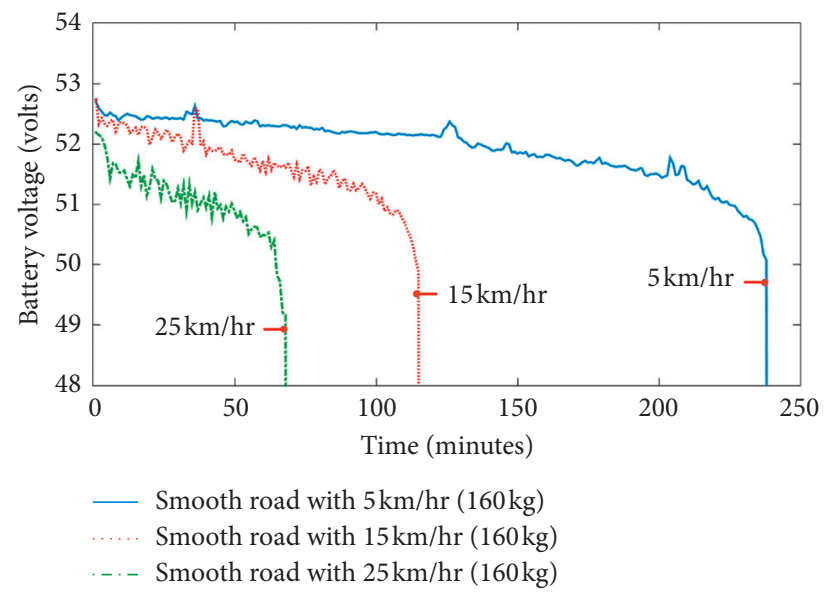

(c)

Figure 12: The obtained results at different speeds with each total weight. (a) $120 \mathrm{~kg}$. (b) $140 \mathrm{~kg}$. (c) $160 \mathrm{~kg}$.

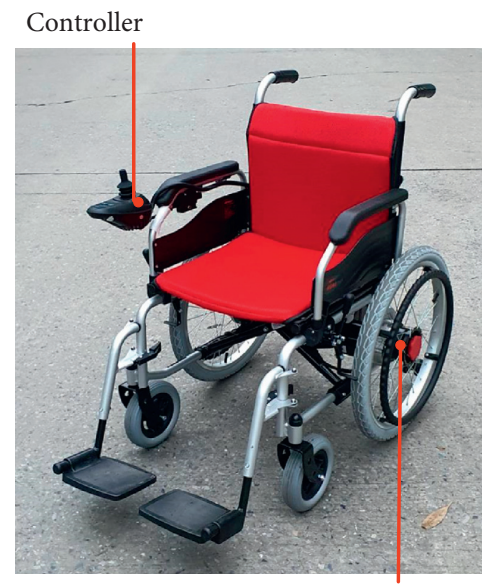

Gear motor

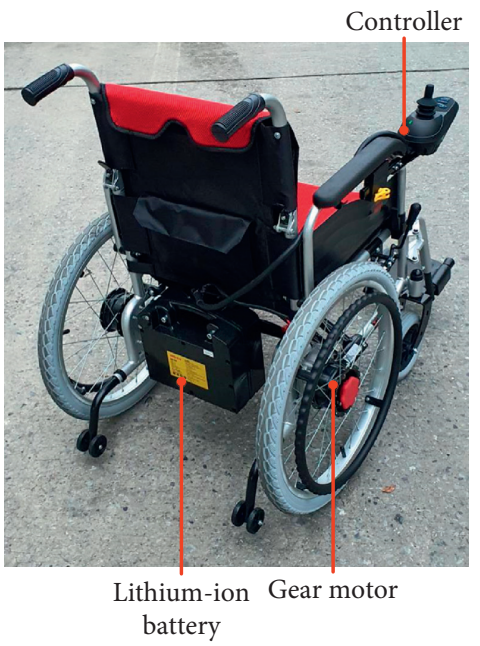

(b)

FIgURE 13: The commercial elderly EV. (a) Frontward isometric view. (b) Backward isometric view.

development. Blynk is a system-user interface that can be accessed with multiple users and is responsive to work in real time. The accumulated data can be used to develop the
EPMD for elderly people, distribute the air quality detection system, and indicate the location of the elderly people and the EPMD. 
TABle 6: Comparison of a commercial elderly EV and the EPMD.

\begin{tabular}{|c|c|c|}
\hline Condition & $\begin{array}{c}\text { The } \\
\text { commercial EV }\end{array}$ & The EPMD \\
\hline Motor & $\begin{array}{l}\text { Gear motor } \\
2 \times 250 \mathrm{~W}\end{array}$ & $\begin{array}{c}\text { BLDC motor } \\
500 \mathrm{~W}\end{array}$ \\
\hline Battery & $\begin{array}{l}\text { Li-ion battery } \\
24 \mathrm{~V}, 20 \mathrm{Ah}, \\
480 \mathrm{Wh}\end{array}$ & $\begin{array}{c}\text { Li-ion battery } \\
48 \mathrm{~V}, 13 \mathrm{Ah}, \\
624 \mathrm{Wh}\end{array}$ \\
\hline Charge time & $7.41 \mathrm{hr}$ & $2.89 \mathrm{hr}$ \\
\hline $\begin{array}{l}\text { Structural } \\
\text { material }\end{array}$ & Aluminum & Carbon steel \\
\hline EV weight & $45 \mathrm{~kg}$ & $70 \mathrm{~kg}$ \\
\hline $\begin{array}{l}\text { Maximum } \\
\text { carry weight }\end{array}$ & $100 \mathrm{~kg}$ & $200 \mathrm{~kg}$ \\
\hline Maximum speed & $5 \mathrm{~km} / \mathrm{hr}$ & $25 \mathrm{~km} / \mathrm{hr}$ \\
\hline $\begin{array}{l}\text { Usable time } \\
(5 \mathrm{~km} / \mathrm{hr})\end{array}$ & $4.98 \mathrm{hr}$ & $3.98 \mathrm{hr}$ \\
\hline Usable distance $(5 \mathrm{~km} / \mathrm{hr})$ & $24.92 \mathrm{~km}$ & $19.92 \mathrm{~km}$ \\
\hline Sensor system & No & Yes \\
\hline EV cost & 770 USD & 880.4 USD \\
\hline
\end{tabular}

The interface display is shown in the Blynk application and is divided into five parts: board status, EPMD status, air quality detection, history graph, and GPS. First, the board status is a hidden part of the normal display, as shown in Figure 14(a), and is responsible for showing the connection of each board. This part consists of the EPMD status board and the air quality detection board, which shows the details of the board in the current status. Next, the EPMD status part is used to show the EPMD status, the emergency alarm, the charging alarm, and the battery voltage level, as shown in Figure 14(b).

In the air quality detection part, shown in Figure 15(a), the real-time parameters of the air quality detection system are shown in terms of temperature, humidity, particulate matter (PM1, PM2.5, PM10), AQI, and $\mathrm{CO}_{2}$. PM2.5 is calculated as the AQI, which is used to consider the health effects according to the AQI criteria of Thailand. For $\mathrm{CO}_{2}$, the ASHRAE 62.1-2013 standard [23,36] of the United States is used to estimate the $\mathrm{CO}_{2}$ value. In Figure 15(b), the history graph part shows the recorded results of all parameters. Historical values can be retrieved for $15 \mathrm{~min}, 1 \mathrm{~h}$, $6 \mathrm{~h}, 1$ day, 3 days, and 1 week. This part can be used to analyse the suitability of outdoor activities of elderly people and to send the data of the graph to the user's e-mail to show the detailed values in terms of the CSV file.

In this research, the air quality parameters were measured by the air quality detection system every minute and recorded on the Google Cloud and Blynk servers between 22 and 27 April 2020. The obtained results are shown in Figure 16. By considering the obtained results, the PMs consist of PM1, PM2.5, and PM10, which change similarly each day of each season. The evaluation of PMs in ambient air is calculated as the AQI to compare the effects on elderly health. The AQI result of PM2.5 is analysed daily, as shown in Figure 16. It is found that the AQI is very high in the morning (6:00 a.m. to 1:00 p.m.). Elderly people should refrain from outdoor activities because they can cause irritation of the eyes and respiratory system. The AQI decreases in the afternoon and evening (1:00-7:00 p.m.) and increases again at night. Therefore, the most suitable time for outdoor activities is in the afternoon and evening (1:00-7:00 p.m.). The characteristic of PM2.5 is not the same every day, and there are unequal values in each month; thus, the air quality detection system is necessary for elderly people to assess the air quality risk by themselves.

The GPS part was designed to inform caregivers and elderly families during normal and accident usage. The GPS data are extracted by the Blynk application on a smartphone, while the EPMD GPS data are extracted by the GPS sensor installed in the EPMD. Both GPS datasets are sent to the EPMD status board. Next, the board sends the GPS data to the Google map widget of the Blynk application, as shown in Figure 17. The results show that GPS data are very accurate when obtained outdoors without an obscuring building.

By considering the deviation of the GPS sensor, the GPS was tested by measuring five test points within the university. The GPS results for the elderly people and the EPMD are compared in Figure 18 and Table 7. The test results show that the GPS data of elderly people are accurate because the data was pulled directly from the smartphone but had a slow response to movement. The GPS of the EPMD was better able to respond to movement but gave a slightly distorted accuracy of approximately 1-2 m. Table 7 shows the latitudes and longitudes of the five test points to compare the measurement capabilities of both types of GPS data, and the distance between the measurement results was calculated as a deviation. The deviation of both GPS values found that the maximum deviation was $2.484 \mathrm{~m}$, and the lowest deviation was $1.013 \mathrm{~m}$, which are considered to be acceptable distances.

By considering the findings for the nearest charging station, the sensor system was tested to calculate the distance between the EPMD and the charging station, which is very beneficial to elderly people when the EPMD battery is low. Elderly people can look for the nearest station and assess their ability to get to the station. In this research, three charging stations were defined: at coordinates 13.731004 and 100.781921 (charging station A), at coordinates 13.729856 and 100.771049 (charging station B), and at coordinates 13.725866 and 100.781105 (charging station C). The five test points were distributed within the university, as shown in Figure 18. The distances between all test points to the three charging stations were calculated using the spherical law of cosines method given by equations (2) and (3) [35], as listed in Table 8. The obtained results show that the calculated values are very close to the actual distances, with a maximum deviation of $0.85 \mathrm{~m}$ and a minimum deviation of $0.23 \mathrm{~m}$, which are considered to be acceptable distances:

$$
\begin{aligned}
& \alpha_{c}=\cos ^{-1}\left[\cos \varphi_{1} \cdot \cos \varphi_{2}+\sin \varphi_{1} \cdot \sin \varphi_{2} \cdot \cos \Delta \lambda\right] \\
& d=2 \pi R \cdot \frac{\alpha_{c}}{360} .
\end{aligned}
$$




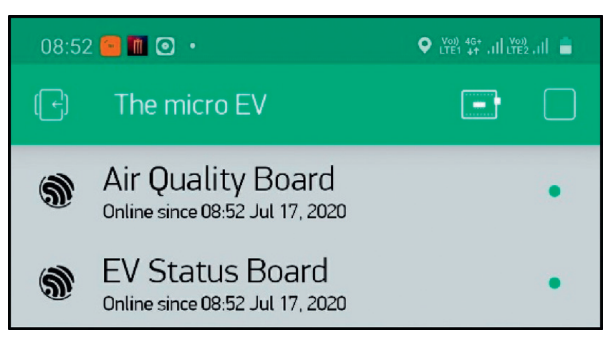

(a)

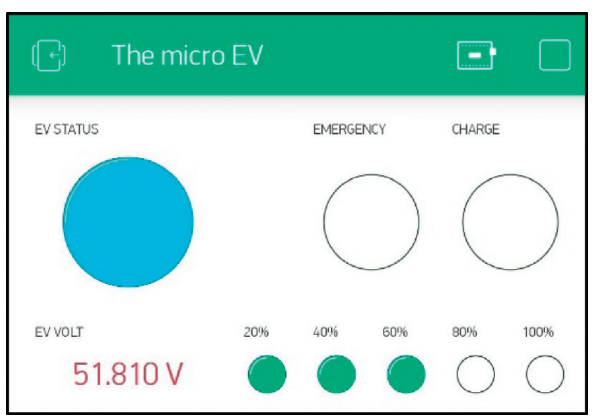

(b)

FIgURE 14: The board status part and the EV status part in the Blynk application. (a) Board status part. (b) EPMD status part.

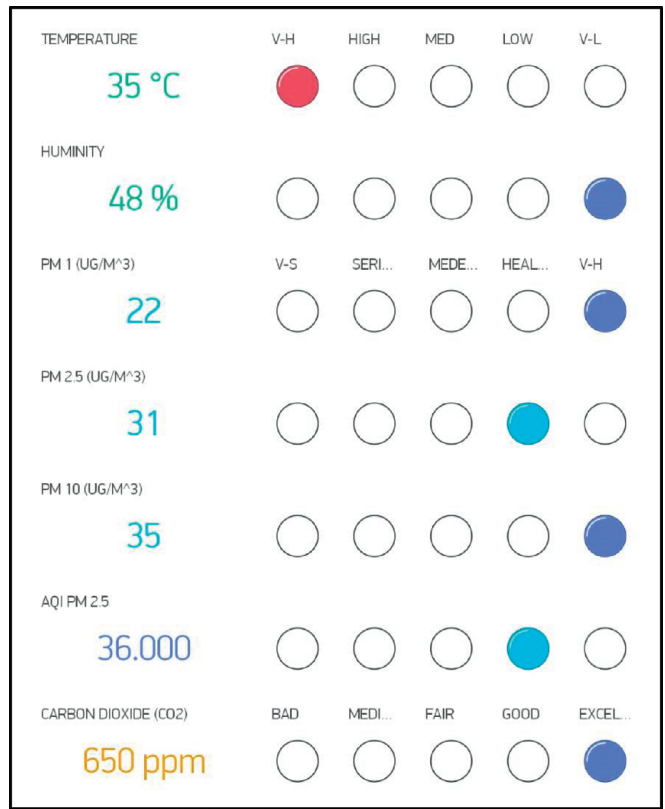

(a)

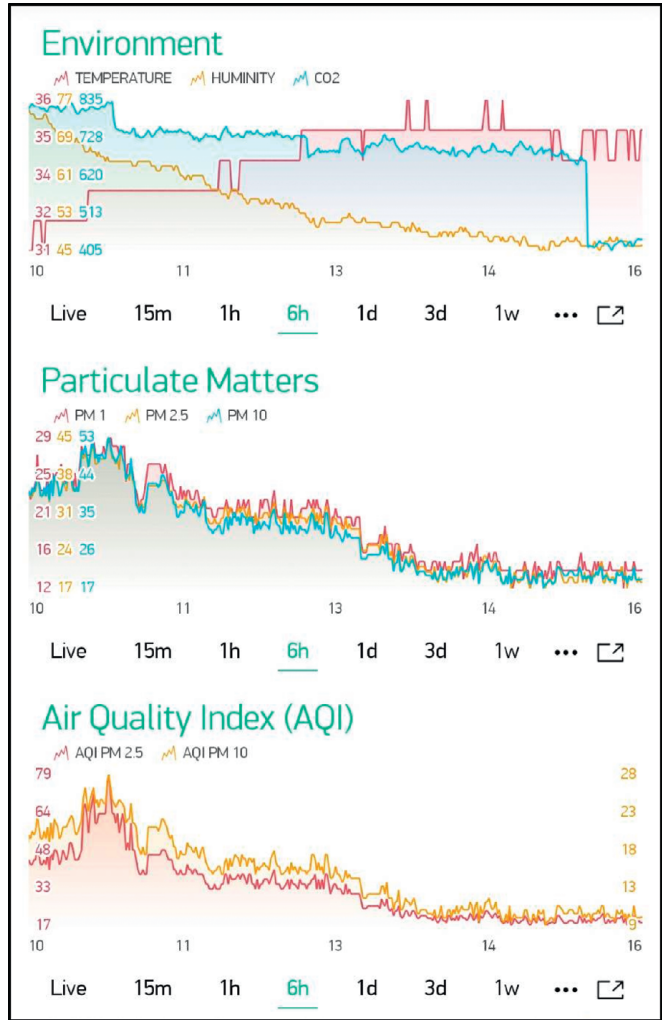

(b)

FIGURE 15: The air quality detection part and the history graph part in the Blynk application. (a) Air quality detection part. (b) History graph part.

3.5. Actual Market of EPMD. EPMD was designed as vehicle for elderly people for traveling indoor and outdoor in daily life. The design was considered from the structural system, selection of materials, and functionalities which were suitable for the elderly people. For commercial development of the EPMD, the chassis should be developed as either aluminum or carbon fiber to have a lighter frame weight, but it must be able to support the same payload. The electric equipment was suitable for use in the village or countryside.
For the sensor system, it was developed in accordance with personal health information for users and can connect EPMD, elderly person, and caregivers together through a mobile application which reduces the burden of the caretaker, increases the safety and freedom of traveling for the elderly person, and creates a distribution of air quality monitoring stations in many areas. When developing into the commercialization, the sensors system must be modified the transmission pattern using a GSM board instead of the 


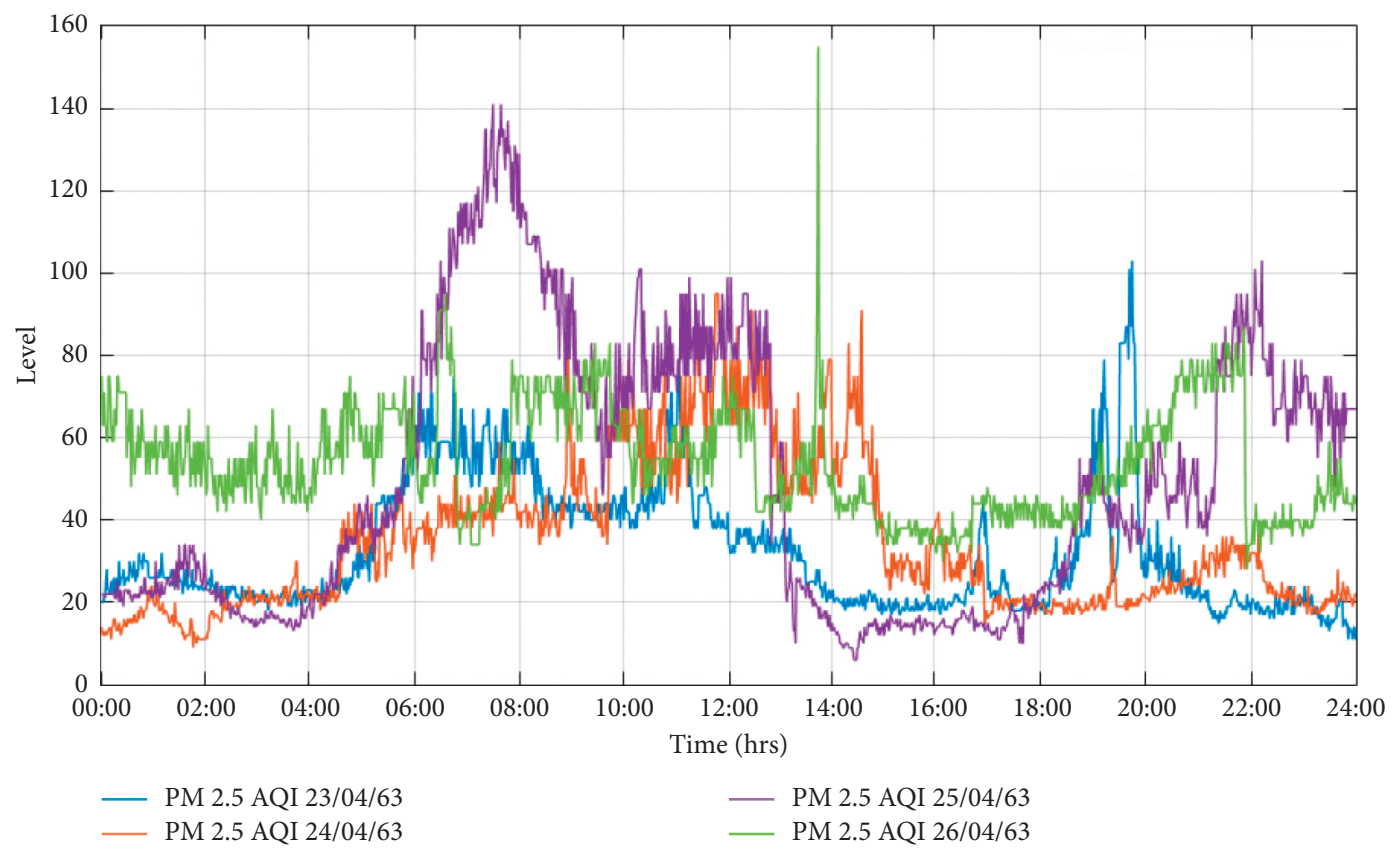

Figure 16: Air quality index for PM 2.5 for 22-27 April 2020.

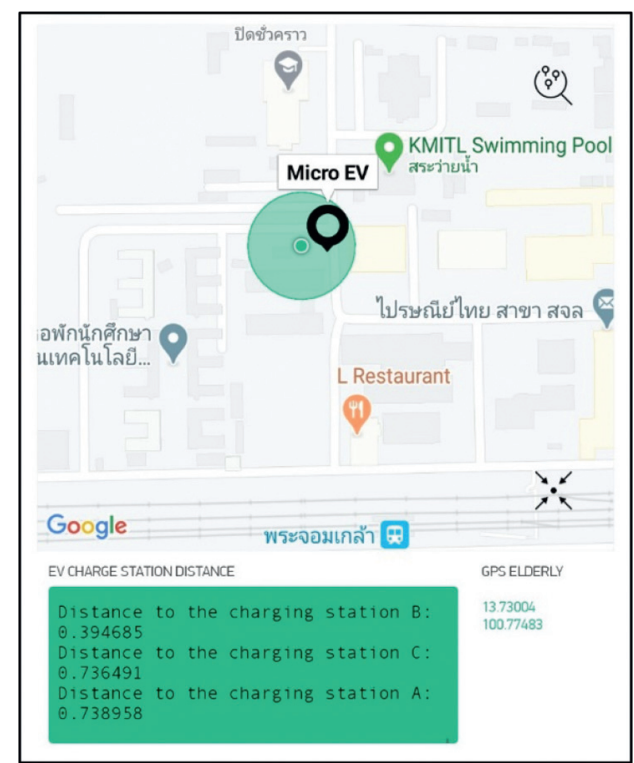

(a)

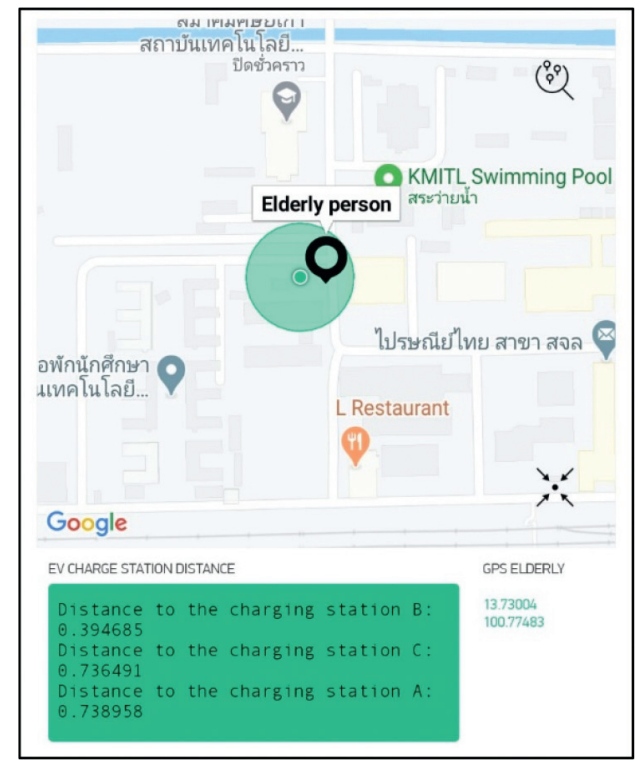

(b)

FIGURE 17: Google map widget of the Blynk application. (a) EPMD GPS. (b) Elderly GPS.

$4 \mathrm{G}$ Wi-Fi router to reduce the cost and power consumption. In addition, in mass production, it is possible to reduce the cost of EPMD.

For the actual market of Micro Electric Vehicle (MEV), according to the statistics of the Department of Land Transport during the year 2015-2019, the use of Battery Electric Vehicle (Bev) is 2854 in which the 60\% were microelectric vehicles. A forecast by the Next-Generation Automotive Center of the Thailand Automotive Institute estimates that the growth of the MEV market has been still increasing by $56 \%$, which is a great opportunity for the commercial development of EPMD in its early stages. This is the beginning of the electric vehicle market in Thailand and globally to be significantly developed in the near future. 


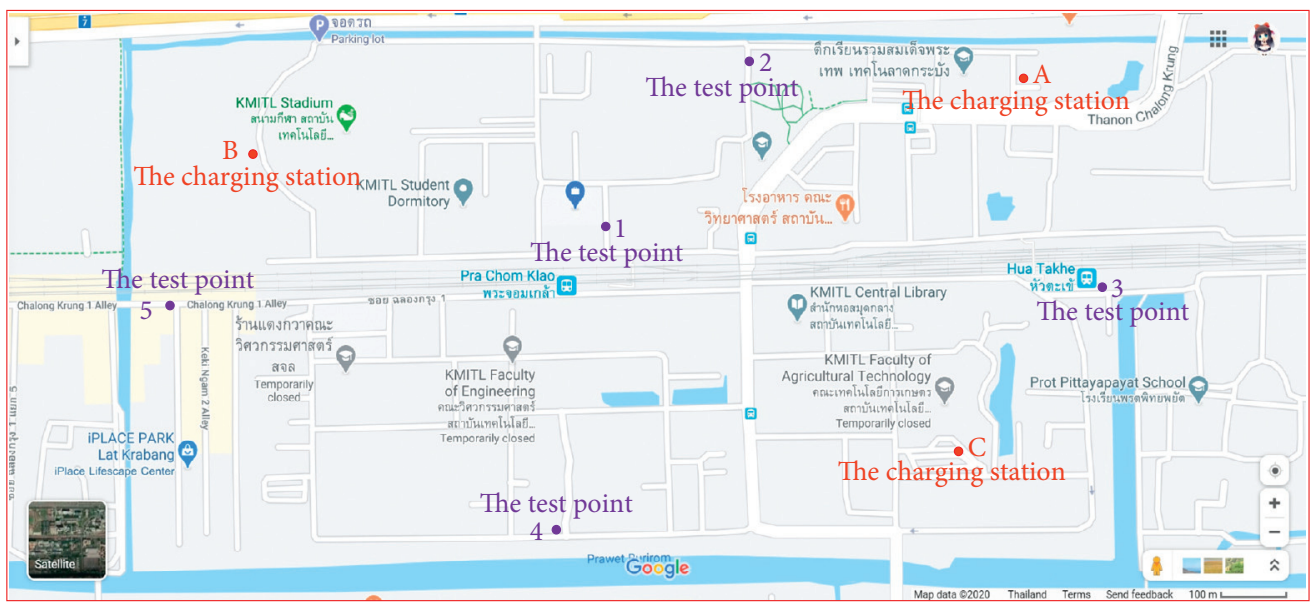

FIGURE 18: Determination of the charging station and measuring point.

TABLE 7: GPS results from five measuring points.

\begin{tabular}{lccc}
\hline The test points & GPS of the elderly person & GPS of the EPMD & Deviation $(\mathrm{m})$ \\
\hline 1 & $13.72897,100.77602$ & $13.72898,100.77600$ & 2.195 \\
2 & $13.73134,100.77807$ & $13.73133,100.77808$ & 1.013 \\
3 & $13.72817,100.78305$ & $13.72818,100.78304$ & 1.965 \\
4 & $13.72476,100.77538$ & $13.72475,100.77538$ & 1.052 \\
5 & $13.72789,100.76984$ & $13.72787,100.76984$ & 2.484 \\
\hline
\end{tabular}

TABLE 8: Distances between the charging stations and the measuring points.

\begin{tabular}{lccccccc}
\hline \multirow{2}{*}{ Test points } & \multicolumn{2}{c}{ Real distance to the charging station $(\mathrm{m})$} & \multicolumn{3}{c}{ Test distance to the charging station (m) } & \multirow{2}{*}{ Maximum deviation (m) } \\
& Station A & Station B & Station C & Station A & Station B & Station C & 0.28 \\
1 & 678.0 & 543.8 & 650.9 & 678.3 & 543.9 & 651.1 & 0.23 \\
2 & 416.9 & 776.6 & 690.4 & 417.1 & 776.9 & 690.6 & 0.54 \\
3 & 336.3 & 1308.0 & 331.2 & 336.4 & 1308.5 & 331.3 & 0.35 \\
4 & 991.1 & 735.8 & 630.4 & 991.4 & 736.1 & 630.6 & 0.85 \\
5 & 1350.0 & 256.5 & 1237.0 & 1350.8 & 256.6 & 1237.1 & \\
\hline
\end{tabular}

\section{Conclusion}

The EPMD was developed as an elderly micromobility vehicle to support travel by the elderly in residential areas at speeds of up to $25 \mathrm{~km} / \mathrm{h}$ and at distances of $20-30 \mathrm{~km} /$ charge. The EPMD structure was designed by optimising shapes, sizes, and thicknesses using SolidWorks software to consider weight, strain, stress, displacement, and cost. The simulation results showed that a $50 \times 25 \mathrm{~mm}^{2}$ carbon steel rectangular pipe with a thickness of $1.6 \mathrm{~mm}$ is appropriate for the structure of the EPMD and can support a total weight of $200 \mathrm{~kg}$. The propulsion power was calculated by the dynamic equation to estimate the BLDC motor size and lithium-ion battery capacity. A 48-V 500-W BLDC motor powered by a $48-\mathrm{V} 13$-Ah 625 -Wh lithium-ion battery was used to drive the rear axle via a chain.

The EPMD was tested at various speeds and weights on several road surfaces. By changing the road surfaces and not the speed, the case of the rough road surface with all total weights provided higher voltage fluctuations and lower total operating time compared with the smooth road surface. The obtained distances of the rough road surface were lower than for the smooth road surface by approximately $11.57 \%$. By changing the total weight and not the speed, the operating time tended to decrease when the total weight was increased. The battery voltage was decreased with respect to the period of use. When the EPMD was driven at high speeds $(15-25 \mathrm{~km} / \mathrm{hr})$, it required more propulsion power, resulting in greater consumption of current and voltage and causing voltage fluctuations and low operating times. By considering the distance obtained using several speeds, although the lowest speed offered the best total operating times, it did not provide the longest distance, because the power loss ratio in the system is high. Later, when comparing the EPMD to a commercial elderly EV with a motor and battery having similar sizes, it was found that the EPMD provides a similar distance value, but the EPMD can dive at a higher speed, which is suitable for both indoor and outdoor use. In addition, the EPMD has a sensor system that increases the safety of the user and reduces the burden on caregivers, providing flexibility to elderly users.

For the sensor system, the EPMD status and air quality detection systems have been designed to increase elderly 
care efficiency. The sensor system receives data from various sensors and sends data to cloud servers to create big data for elderly health services. The data are shown via the interface applications and are collected using various servers, including Blynk, LINE Notify, and Google Cloud. The EPMD status, air quality parameters, and health impacts are shown in the real-time Blynk interface via the smartphone applications of elderly people, caregivers, and elderly families. The EPMD status is displayed, the risks of outdoor activities are assessed, the best times for outdoor activities are considered, and alerts for emergencies are produced. The location and air quality are recorded in a database in the Google Cloud server to analyse the changes in air quality in the area and to make air quality predictions. The AQI evaluation shows that a suitable time for outdoor activities is between 1:00 p.m. and 7:00 p.m., because this time interval has the lowest AQI of the day. However, each day or area has a different air quality change, so an assessment of air quality risks using the EPMD status and air quality monitoring system is a good and very useful option. Finally, the system for finding the nearest charging station is beneficial to the user when the battery is low and helps to manage energy efficiently and safety. Users can find the nearest charging station from the Blynk interface and assess their ability to get to the station.

The proposed EPMD can be developed in the future research in aspect of an autonomous pit road avoiding system. Machine learning will be applied to avoid obstacles and interpret data from the user interface to prevent dangers that may occur while driving. In addition, a charging station distance system will be developed to determine the best route of travel to the charging station.

\section{Abbreviations}

P: Propulsion power

$F_{t}$ : Total traction force

$F_{r}$ : Resistance force

M: Total mass

$f_{m}:$ Mass factor

$\alpha_{a}:$ Acceleration

$V: \quad$ Speed

$\mathrm{C}_{\mathrm{rr}}$ : Coefficient of rolling resistance

g: Gravity

$\rho$ : Air density

A: Vehicle frontal area

$C_{\mathrm{d}}$ : Aerodynamic drag coefficient

$V_{\mathrm{w}}$ : Wind speed

$\theta$ : Road slope angle

$\varphi_{1}$ : Latitude of first position

$\varphi_{2}$ : Latitude of second location

$\Delta \lambda$ : Longitude difference of both positions

$\mathrm{d}$ : Distance on the earth surface

$\mathrm{R}:$ World radius $(6371 \mathrm{~km})$

$\alpha_{c}$ : Central subtended angle.

\section{Data Availability}

No data were used to support this study.

\section{Conflicts of Interest}

The authors declare that they have no conflicts of interest.

\section{Acknowledgments}

This work was supported by the King Mongkut's Institute of Technology Ladkrabang.

\section{References}

[1] E. Rudnicka, P. Napierała, A. Podfigurna et al., "The World Health Organization (WHO) approach to healthy ageing," Maturitas, vol. 139, pp. 6-11, 2020.

[2] J. Woo, R. Yu, K. Cheung et al., "How much money is enough? Poverty and health in older people," The Journal of Nutrition, Health and Aging, vol. 24, pp. 1111-1115, 2020.

[3] J. Pertanika, "Wellbeing of older people in iran: an application of the global agewatch index," Pertanika Journal of Social Science and Humanities, vol. 28, no. 1, pp. 409-424, 2020.

[4] J. Dikken, R. F. van den Hoven, W. H. van Staalduinen, L. M. Hulsebosch-Janssen, and J. van Hoof, "How older people experience the age-friendliness of their city: development of the age-friendly cities and communities questionnaire," International Journal of Environmental Research and Public Health, vol. 17, 2020.

[5] C. Phillipson and T. Buffel, "Developing age-friendly cities: policy opportunities and challenges," Journal of Elder Policy, vol. 1, no. 1, pp. 137-154, 2020.

[6] F. Pilo and R. Jaffe, "Introduction: the political materiality of cities," City \& Society, vol. 32, no. 1, pp. 8-22, 2020.

[7] M. Eisenbarth, M. Wegener, R. Scheer et al., "Toward smart vehicle-to-everything connected powertrains: driving real component test benches in a fully interactive virtual smart city," IEEE Vehicular Technology Magazine, 2020.

[8] J. Richter, J. Lorenz, M. Costantino et al., "Dynamic indoor navigation and orientation system for people with impairments," in Proceedings of the Conference on Mensch und Computer (MuC '20), pp. 473-477, Germany, September 2020.

[9] S. Lee, M. Reddie, C.-H. Tsai et al., "The emerging professional practice of remote sighted assistance for people with visual impairments," in Proceedings of the 2020 Chi Conference on Human Factors in Computing Systems (Chi '20), pp. 1-12, Honolulu, HI, USA, April 2020.

[10] J. Huang, M. Kinateder, M. J. Dunn, W. Jarosz, X.-D. Yang, and E. A. Cooper, "An augmented reality sign-reading assistant for users with reduced vision," PLoS One, vol. 14, no. 1, 2019.

[11] S. Shirai and Y. Takahashi, "Personal mobility vehicle user's psychological reaction to surrounding people," in Proceedings of the 2018 18th International Conference on Control, Automation and Systems (ICCAS), pp. 1730-1735, Daegwallyeong, October 2018.

[12] C. D. Harper, C. T. Hendrickson, S. Mangones, and C. Samaras, "Estimating potential increases in travel with autonomous vehicles for the non-driving, elderly and people with travel-restrictive medical conditions," Transportation Research Part C: Emerging Technologies, vol. 72, pp. 1-9, 2016.

[13] N. Maehara, M. Shavandi, and Y. Takahashi, "Concept design of personal mobility vehicle," in Proceedings of the 2017 17th International Conference on Control, Automation and Systems (ICCAS), pp. 1525-1530, Jeju-do, South Korea, October 2017. 
[14] R. C. P. Wong, W. Y. Szeto, L. Yang, Y. C. Li, and S. C. Wong, "Public transport policy measures for improving elderly mobility," Transport Policy, vol. 63, pp. 73-79, 2018.

[15] V. Sirivat, "A new era of Thai public sector toward asean community: a comparative study between the Ministry of labour and the Ministry of social development and human security," Kasem Bundit Journal, vol. 20, 2019.

[16] A. Tsoukanelis, E. Genitsaris, D. Nalmpantis, and A. Naniopoulos, "Conjoint analysis for the optimization of a potential flexible transport service (FTS) in the region of zagori, Greece," in Data Analytics: Paving the Way to Sustainable Urban Mobility, E. Nathanail and I. Karakikes, Eds., Vol. 879, Springer, Berlin, Germany, 2019.

[17] G. Papadima, E. Genitsaris, I. Karagiotas, A. Naniopoulos, and D. Nalmpantis, "Investigation of acceptance of driverless buses in the city of Trikala and optimization of the service using Conjoint Analysis," Utilities Policy, vol. 62, 2020.

[18] T. H. Tran, T. T. Nguyen, Z. M. Yuldashev, E. V. Sadykova, and M. T. Nguyen, "The method of smart monitoring and detection of sleep apnea of the patient out of the medical institution," Procedia Computer Science, vol. 150, pp. 397-402, 2019.

[19] B. Bongisizwe, M. Maredi, D. Deon, M. Solly, and M. Topside, "ZigBee healthcare monitoring system for ambient assisted living environments," International Journal of Communication Networks and Information Security, vol. 11, pp. 85-92, 2019.

[20] Z. Wang, F. Wang, H. Liu, Z. Qian, and Z. Bi, "Design of human health monitoring system based on NB-IoT," in Proceedings of the 2019 IEEE 3rd Advanced Information Management, Communicates, Electronic and Automation Control Conference (IMCEC), pp. 6-9, Chongqing, China, October 2019.

[21] J. YangY. Liu et al., "Assistive and monitoring multifunctional smart crutch for elderly," in Proceedings of the 2019 IEEE Intl Conf on Dependable, Autonomic and Secure Computing, Intl Conf on Pervasive Intelligence and Computing, Intl Conf on Cloud and Big Data Computing, Intl Conf on Cyber Science and Technology Congress (DASC/PiCom/CBDCom/CyberSciTech), pp. 397-401, Fukuoka, Japan, August 2019.

[22] J. Cui, P. Song, W. Li et al., "Design of a health care platform for the elderly," in Proceedings of the 2016 IEEE International Conference on Robotics and Biomimetics (ROBIO), pp. 661666, Qingdao, China, December 2016.

[23] J. Kulsiriruangyos, V. Rattanawutikul, P. Sangsartra, and D. Wongsawang, "Home security system for alone elderly people," in Proceedings of the 2016 Fifth ICT International Student Project Conference (ICT-ISPC), pp. 65-68, Nakhon Pathom. Thailand, May 2016.

[24] C. Fulvio, M. Teodoro, M. Carmelo, and C. Pino, "SmartBike: an IoT crowd sensing platform for monitoring city air pollution," International Journal of Electrical and Computer Engineering, vol. 7, 2017.

[25] G. B. Fioccola, R. Sommese, I. Tufano, R. Canonico, and G. Ventre, "Polluino: an efficient cloud-based management of IoT devices for air quality monitoring," in Proceedings of the 2016 IEEE 2nd International Forum on Research and Technologies for Society and Industry Leveraging a better tomorrow (RTSI), pp. 1-6, Bologna. Italy, 2016.

[26] S. Kumar and A. Jasuja, "Urban climate monitoring system based on IoT using Arduino Uno," Advances in Computer Science and Information Technology (ACSIT), vol. 4, pp. 118-121, 2017.
[27] A. Doni, M. V. Chidananda Murthy, and Dr M. Z. Kurian, "Survey on multi sensor based air and water quality monitoring using IoT," Indian Journal of Scientific Research, vol. 17, no. 2, pp. 147-153, 2018.

[28] O. Kennedy, E. Noma-Osaghae, O. Modupe, S. John, and O. Oluwatosin, "A. Smart air pollution monitoring system," International Journal of Civil Engineering and Technology (IJCIET), vol. 9, no. 9, pp. 799-809, 2018.

[29] D. V. Mahammad, "Design and implementation of IoT based portable outdoor dust density monitoring system," International Research Journal of Engineering and Technology (IRJET), vol. 612 pages, 2019.

[30] R. Firdaus, M. A. Murti, and I. Alinursafa, "Air quality monitoring system based internet of things (IoT) using LPWAN LoRa," in Proceedings of the 2019 IEEE International Conference on Internet of Things and Intelligence System (IoTaIS), pp. 195-200, Bali, Indonesia, November 2019.

[31] V. Choudhary, J. H. Teh, V. Beltran, and H. B. Lim, “AirQ: a smart IoT platform for air quality monitoring," in Proceedings of the 2020 IEEE 17th Annual Consumer Communications \& Networking Conference (CCNC), pp. 1-2, Las Vegas, NV, USA, January 2020.

[32] N. A. Zakaria, Z. Zainal Abidin, and N. Harum, "Wireless Internet of things-based air quality device for smart pollution monitoring," International Journal of Advanced Computer Science and Applications (IJACSA), vol. 9, no. 11, 2018.

[33] K. George, "An evaluation of the concept of rolling resistance," Journal of Terramechanics, vol. 36, no. 3, pp. 159-166, 1999.

[34] G. Descornet, W. Meyer, and J. Reichert, "Road-surface influence on tire rolling resistance," in STP1031-EB Surface Characteristics of Roadways: International Research and Technologies, pp. 401-415, ASTM International, West Conshohocken, PA, USA, 1990.

[35] K. Hassan, A. Sam, and D. Machuve, "Algorithm to identify location of incidents in public buses and respective nearest authority using spherical cosine rule," International Journal of Technology Enhancements and Emerging Engineering Research, vol. 1, no. 2, 2013.

[36] M. Zaatari, A. Novoselac, and J. Siegel, "Impact of ventilation and filtration strategies on energy consumption and exposures in retail stores," Building and Environment, vol. 100, pp. 186-196, 2016. 